\title{
Advances in HF, VHF, and UHF Systems and Technology
}

Robert Caverly, Villanova University

Gary Breed, AY Technologies LLC

William H. Cantrell, MIT Lincoln Laboratory

Murat Eron, Wireless Telecom Group

Jose A. Garcia, University of Cantabria

Nisha Kondrath, Villanova University

Dan Myer, Communication Power Corporation (CPC)

Maria N. Ruiz, University of Cantabria

John L. B. Walker, Integra Technologies, Inc. 


\section{INTRODUCTION}

In the March 2002 Transactions of Microwave Theory and Techniques (T-MTT), Frederick Raab, chair and founder of the HF-VHF-UHF Technology technical committee of the MTT Society (Technical Committee 17), organized an extensive overview paper titled 'HF, VHF, and UHF Systems and Technology'[1]. The paper started with the early $20^{\text {th }}$ century notion that frequencies above approximately 1.5 MHz (200 meters and down [2]) were useless for communications, a fact soon discovered to be wrong as experimenters and amateur radio enthusiasts showed the utility of the higher frequencies. The paper reviewed HF through UHF communications techniques and technologies, various propagation modes and a number of systems and applications below $1000 \mathrm{MHz}$. There have been a number of advances in this frequency range in the intervening years, some of them quite striking, as well as new applications and other applications not mentioned in the paper; updating this article on HF, VHF and UHF technology is the major focus of this paper. In addition to updates on some of the material in the original paper, new technologies and/or better understanding of electromagnetic behavior have occurred and these are included in this paper.

The 2002 T-MTT paper covered various propagation modes over the HF through UHF frequency range where the earth's ionosphere and troposphere can significantly impact communications. For frequencies below approximately, $50 \mathrm{MHz}$, the ionosphere can refract RF signals, resulting in propagation distances of thousands of kilometers. The ultimate distance depends on numerous factors such as incident angle, carrier frequency and time of day (solar intensity influences the ionization and hence the refracting capabilities of the ionosphere). Above 30-50 MHz, the troposphere impacts wave propagation. Long distance signal propagation can be achieved via diffraction and scattering from irregularities in the troposphere. Over the last twelve years, new communication technologies based on signal processing techniques and related communication protocols, have been introduced that can minimize some of the undesirable propagation effects in both the ionosphere and troposphere. The fundamentals of the propagation modalities have not changed, however, so updates in this area of HF through UHF wave propagation will not be covered in this article. The reader is encouraged to review other publications such as the IEEE Communications Magazine for in-depth discussions of new communication techniques. The primary focus of this paper is to update information on solidstate device technology, amplifiers of various types and power levels, magnetic resonance imaging, DC-DC power converters, EMC and ground penetrating radar. 


\section{RF POWER TRANSISTORS}

In the 2002 article [1], the dominant RF power transistors in the HF/VHF/UHF frequency range were Si VDMOS transistors and Si bipolar transistors for CW and pulsed applications, respectively. While these two types of transistors are still being manufactured, neither is likely to be the engineer's first choice today for the basis of any new design. Si LDMOS has many advantages over both Si VDMOS and Si BJT and is now the dominant technology for most new designs in the HF to UHF frequency range, and although there are some specialized applications for which GaN HEMT devices offer better performance, these will be discussed later.

Compared with Si VDMOS, LDMOS has lower source inductance and hence higher gain since the source is grounded with many $p+$ sinkers through the Si die rather than requiring lengthy bond wires. It has a lower output capacitance that raises the required impedance that the output matching network must present to the transistor. This makes the achievement of higher power over wider bandwidths easier, and it eliminates the need for costly and environmentally unfriendly $\mathrm{BeO}$ packages because the underside of the die is now the source rather than the drain. In fact, many LDMOS power transistors are available in plastic packages that further reduce their cost. Compared with Si BJT's, LDMOS has higher gain, not just because of the lower source inductance but also because they do not require emitter ballast resistors to prevent thermal runaway. Emitter ballast resistors significantly reduce the RF gain due to their negative feedback effect. LDMOS is also more linear than bipolar devices as the latter have an inherent exponential collector current dependence upon base-emitter voltage. Finally, BJT RF power transistors require a $\mathrm{BeO}$ package because the underside of the die is the collector.

GaN HEMT devices have emerged from the research laboratories and are now commercially available from many manufacturers worldwide, in fact there are many more companies manufacturing GaN HEMT devices than Si LDMOS. Why the huge interest in GaN? $\mathrm{GaN}$, like $\mathrm{SiC}$, is a wide band-gap semiconductor, which means that the breakdown electric field is about a factor of ten higher than in Si. This means that a GaN HEMT device having similar dimensions to a Si LDMOS transistor will have a drain-source breakdown voltage approximately ten times that of the LDMOS device. This fact alone means that, in theory, a GaN device should be able to generate almost ten times the output power of an LDMOS device having the same gate length and width. This is an over-simplistic analysis but it illustrates the potential of GaN for RF power transistors. In addition, $\mathrm{GaN}$ has been successfully combined with $\mathrm{AlGaN}$ in the epitaxial growth chamber. A 2-Dimensional Electron Gas (2DEG) is formed at the interface of the AlGaN and GaN epitaxial layers with an electron concentration that is ten times larger than in the equivalent LDMOS device. This translates into a higher saturated drain current that increases the output power capability of GaN HEMT devices compared to LDMOS. Furthermore, the GaN layer has no intentional doping with the result that the mobility of electrons flowing in the GaN layer is very high, hence the origin of the name High Electron Mobility Transistor (HEMT). The 
high electron mobility reduces the on-resistance and increases the transconductance, and this facilitates the achievement of higher efficiency and a higher cutoff frequency.

With so many advantages for GaN, then what's the catch? The problem is GaN has a similar thermal conductivity to that of Si (1.3 compared with $\left.1.5 \mathrm{~W} / \mathrm{cm}^{2} \mathrm{~K}\right)$ which means that the ten-fold higher power density potential of $\mathrm{GaN}$ for RF power transistors cannot be realized in practice except in pulsed applications. This problem can be mitigated slightly by the fact that GaN devices can be operated at higher junction temperatures than their Si counterparts for the same MTBF since GaN is a wide band-gap semiconductor, but nowhere near high enough to fully compensate for the higher power density. A further problem is that high quality semiinsulating GaN substrates are not readily available so the GaN epitaxial layers are usually grown on a SiC substrate when good heat dissipation is required, or on a Si substrate in less demanding applications. The thermal conductivity of $\mathrm{SiC}$ is about four times higher than $\mathrm{GaN}$ and this greatly helps to realize the potential benefits of $\mathrm{GaN}$ for RF power transistors, but there is still a need for better heat dissipation, especially for high power CW applications. To this end, research is underway on the use of diamond as a substrate to grow the GaN epitaxial layers [2] since diamond has a ten-fold higher thermal conductivity than SiC. Fig. 1 shows a cross-section of a typical GaN HEMT device along with its equivalent circuit elements.

\section{Drain \\ Gate \\ Source}

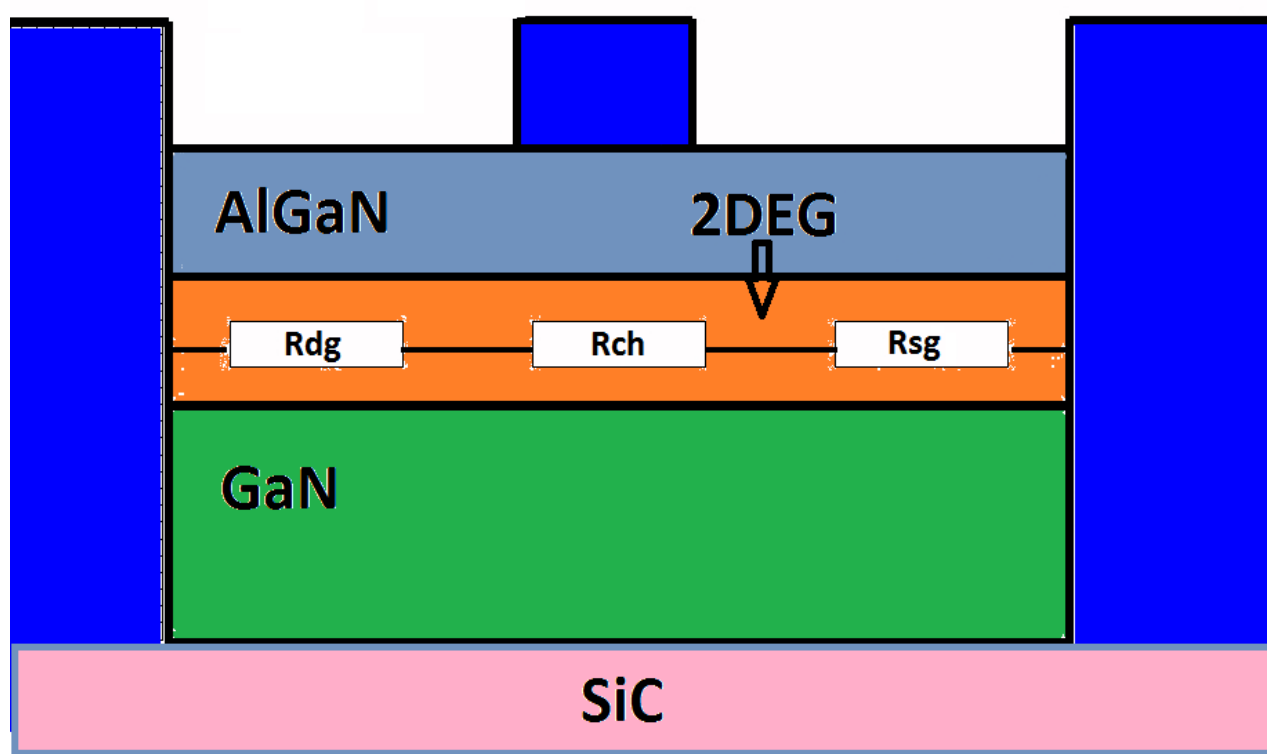

Fig. 1. Cross section of GaN HEMT showing two dimensional electron gas (2DEG) channel resistance equivalent circuit elements [from 3].

A key consideration in the use of $\mathrm{GaN}$ is cost. Obviously, $\mathrm{SiC}$ substrates are more expensive than Si but, to make matters worse, the largest $\mathrm{SiC}$ substrate size in regular production is 4" (with the move to 6” in progress), while LDMOS devices are produced on 8” substrates.. 
On the positive side, GaN HEMT devices have a higher power density, so the die size per Watt is smaller, which mitigates the cost problem to some extent. Nevertheless, on a \$/W basis GaN HEMT devices cost more than their LDMOS counterparts, which raises the question: what applications in the HF/VHF/UHF frequency range do GaN HEMT devices offer sufficient performance advantage compared to LDMOS that can justify their higher cost? There are two such applications, namely high power ultra-wide bandwidth amplifiers, and very high-efficiency narrow-band amplifiers. Because GaN on SiC HEMT devices have a much higher power density than LDMOS, their capacitance per Watt is much lower, and this is a key requirement for high power, ultra-wide bandwidth amplifiers. As an example of the state of the art, recent work [4] has reported 100W CW minimum output power at less than $1 \mathrm{~dB}$ compression over the decade bandwidth of $100-1000 \mathrm{MHz}$ with a minimum efficiency of $55 \%$ and $15 \mathrm{~dB}$ gain at all frequencies. In the case of narrowband, very high-efficiency amplifiers, $93.6 \%$ at $26.8 \mathrm{~W}$ has been recorded at $13.56 \mathrm{MHz}$ using class $\mathrm{E}$ [5]. The very high efficiency is a consequence of GaN HEMTs having both a lower capacitance and lower on-resistance per Watt.

Diamond is not only an excellent substrate for heat dissipation but it is also a semiconductor in its own right. It has many advantages compared with Si and GaN such as much better thermal conductivity, lower dielectric constant leading to lower capacitance, and a wider band-gap than even that of GaN. All of these attributes suggest that diamond should be a better semi-conductor for RF power transistors than either Si or GaN, and research is underway [6]. However, to date the power per mm of gate periphery remains well below what has been achieved with GaN.

\section{AMPLIFIERS}

\section{Low to Medium Power Amplifiers}

Amplification is a necessity in almost all HF/VHF/UHF applications. Given the wide range of applications at these frequencies, amplifier technology shows a very wide range of device choices, topologies and power levels. One can identify two categories in very broad terms in this band: low noise amplifiers (LNAs) and power amplifiers (PAs). While LNAs are essential functional blocks of any receiver system, power amplifiers are utilized for transmitting data or signals in conjunction with an antenna or cable arrangement, or for an industrial application such as heating or Magnetic Resonance Imaging (MRI).

Until recently, most HF/VHF/UHF communication and broadcasting traditionally involved narrow channels and single carriers. Combined with early adoption of radio as a mobile device, this led to the use of the most efficient power amplifier topologies and the modulation schemes to accommodate them. We have seen wide use of class AB, $\mathrm{C}$ and numerous switching mode or tuned power amplifiers that met the efficiency requirements. 
Lower frequencies make it easier to operate the transistors closer to ideal switching characteristics, where the shunt capacitance has minimal effect and other parasitics are less likely to distort the waveform. Constant-amplitude modulation methods such as CW, FM and doublesideband, and full carrier AM do not require particularly linear amplifiers for good operation, thus switching mode power amplifiers have been widely used for these applications. Rapid improvements and availability of devices with higher breakdown voltages have also made switching mode designs more attractive.

HF and VHF frequencies have also made some components and amplifier topologies more feasible compared with higher frequencies. These include use of ferrites and transformers for adjusting impedance levels and combining multiple power stages. Compared with tuned circuits, these designs can be very broadband. When combined with new high power transistors, compact, high power amplifier modules can be designed (Fig. 2).

Rapid moves to digital technology in radio applications since the 1990's have profoundly influenced radio transmitter technology. Emphasis has shifted to not just higher efficiency, but also linearity. Even though the first global digital technology, GSM, employed constant amplitude GMSK modulation, there are still limits on how much distortion could be tolerated both in-band and into closely packed adjacent channels. The next generation of digital technology, CDMA, with its higher order modulation scheme for higher data rates, required very linear transmitter power amplifiers. This created quite a challenge for power amplifier designers. Base station equipment needed to handle very high power levels for multiple carriers in a linear manner without causing interference between channels. Handsets needed to transmit in a more linear manner with minimal drain on the batteries. These requirements are often contradictory. Raw device linearity cannot be improved without moving to class A amplifier designs and oversizing the transmitter amplifiers, not just a very expensive solution, but also enormously inefficient [7-9].

Eventually, techniques were developed to improve the linearity of amplifiers by adding external circuitry, first analog and then digital. Such linearization made it possible to push amplifiers into more efficient operating regimes with little concern over distortion and signal leakage into adjacent channels. Linearization techniques have become very powerful and available off the shelf so that the most recent trend in RF PA design is to use efficient switchingtype circuit topologies in conjunction with linearization to achieve the best of both worlds, linear power and efficiency. Combining Doherty topology (Fig. 3 [10]) with digital or analog linearization yields efficient operation over a much larger operating range. Incorporating compact but smart and complex control circuitry with these amplifiers enables high performance over wider operating conditions and extracts more of the available performance.

In the medium to higher power realm, highly linear PAs for use in MRI are of current interest. The amplifier shown in Fig. 4 was designed by Green Mountain Radio Research and 
produced under license by Communication Power Corporation (CPC). It incorporates class-E RF PAs, class-S modulators, and a digital signal processor [11]. This PA produces an output power of up to $700 \mathrm{~W}$ at $42.6 \mathrm{MHz}$ and maintains an efficiency of $70 \%$ for most output amplitudes. Its linearity is better than that of a conventional class-AB linear amplifier.

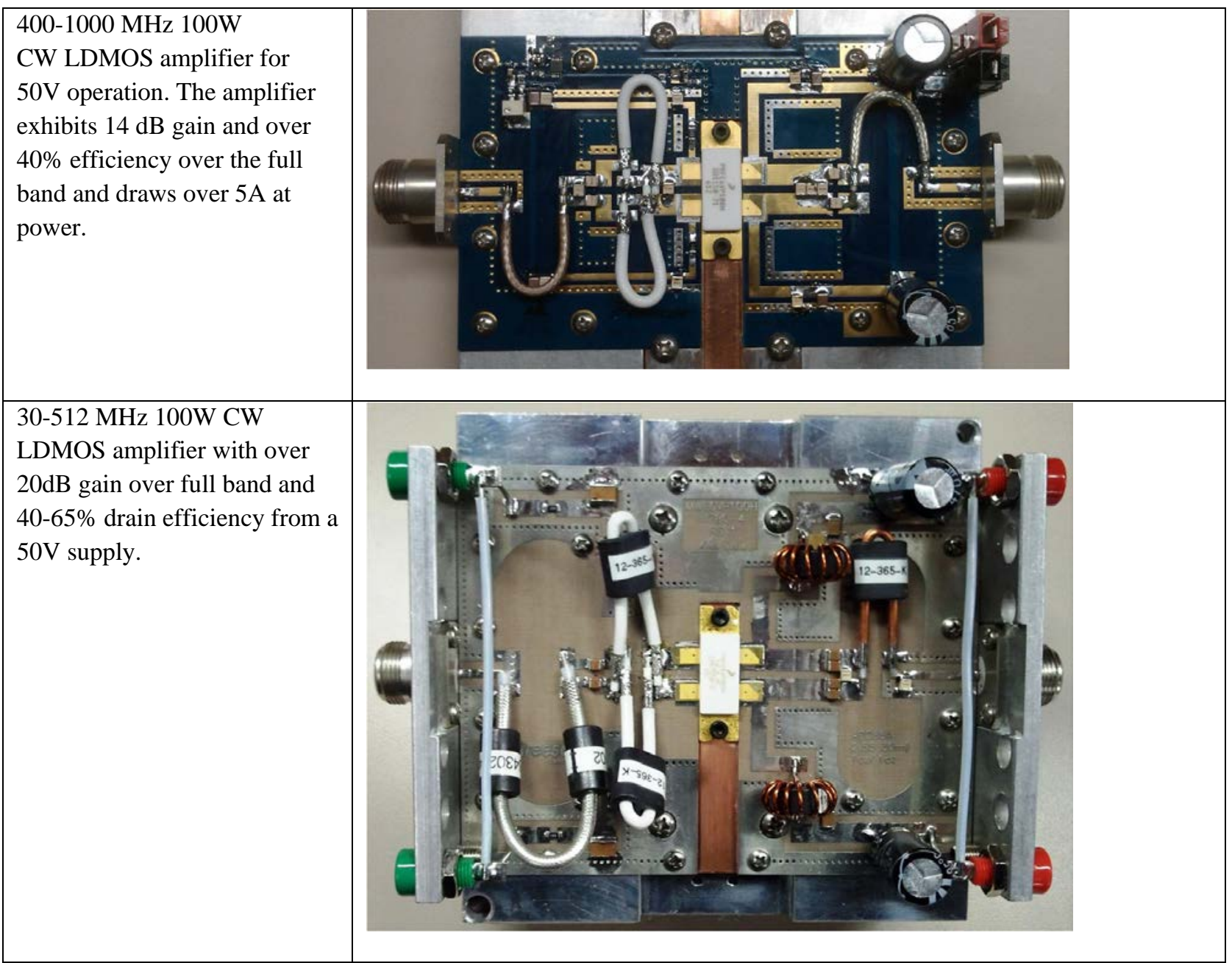

Fig. 2. Examples of medium and high power single device package LDMOS HF-UHF amplifiers. Courtesy of Freescale Semiconductor. 


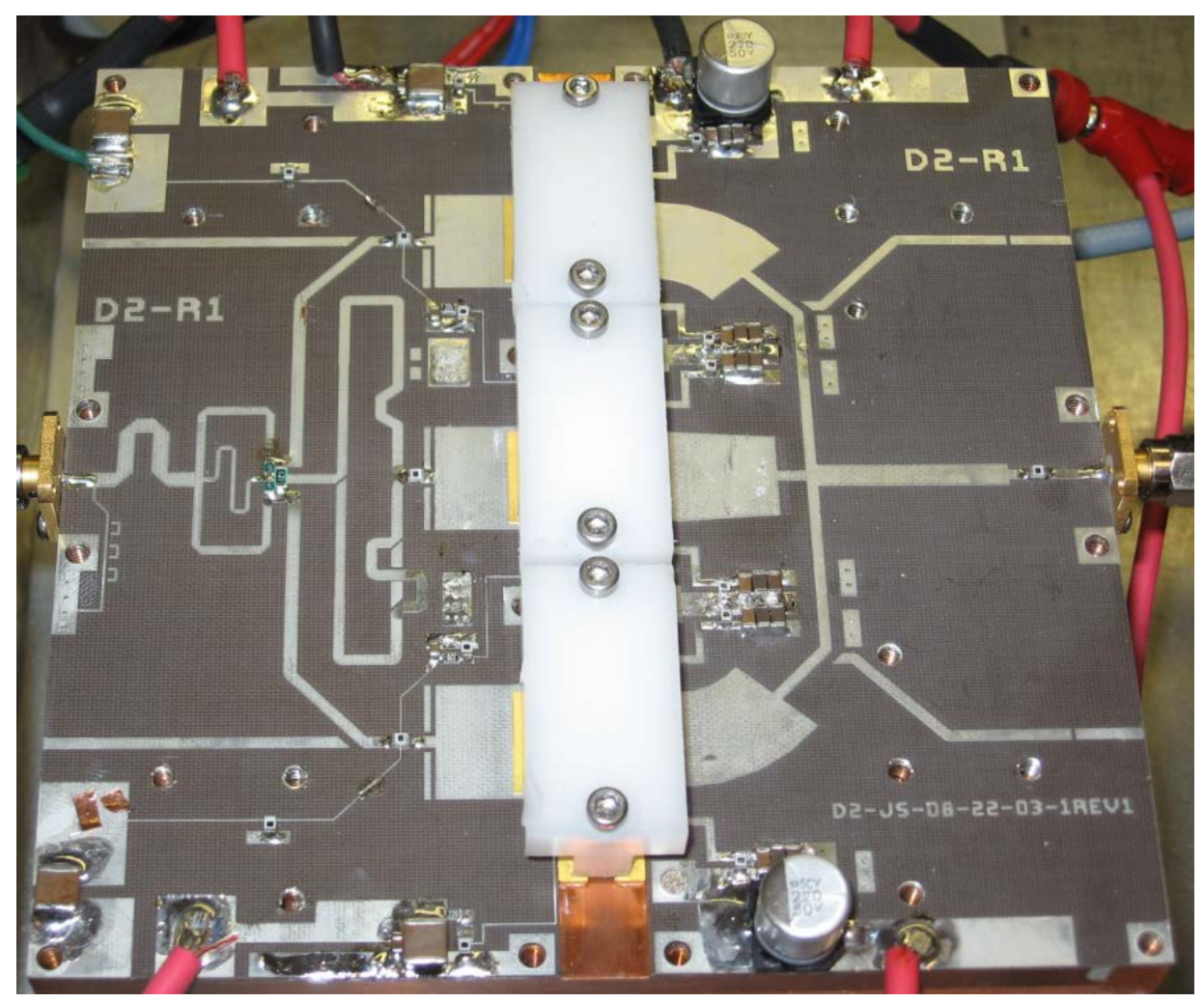

Fig. 3. Single-board $450 \mathrm{~W}$ peak power Doherty amplifier [10]. Used with permission.

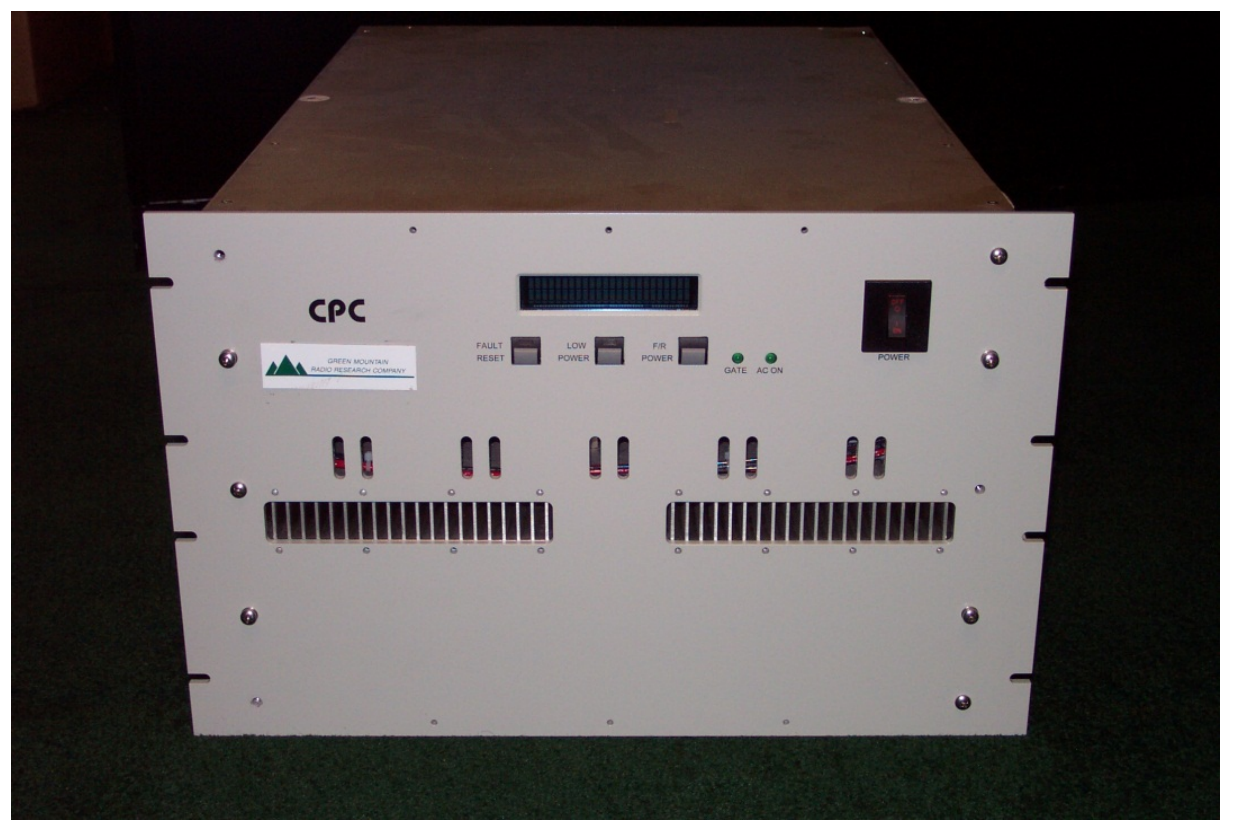

Fig. 4. High-efficiency amplifier for MRI. Courtesy of GMRR [11]. 
High Power Amplifiers in the ISM Market

The Industrial, Scientific and Medical (ISM) market for RF Power amplifiers include Magnetic Resonance Imaging (MRI), Nuclear Magnetic Resonance (NMR) Spectroscopy and Particle Acceleration among other applications. RF power amplifiers are an essential subsystem in MRI scanners and NMR spectrometers (see the next section for more details on the RF aspects of MR technology). The past decade has seen the highest field strength in whole body MR scanners go from 9.4 to 10.5 Tesla. This increase in field strength offers improved image resolution and signal to noise ratio. A significant challenge with higher field strengths is maintaining a uniform RF (B1) field across the Region of Interest (ROI) in the patient. An effective measure to facilitate a uniform B1 field is to use an array of RF power amplifiers as opposed to one. By adjusting the output power and relative phase of multiple RF power amplifiers, the RF field can be brought to uniformity (known as B1 shimming) by spatially combining (either constructively or destructively) the outputs. An example of a high power PA for MR use is shown in Fig. 5. The PA is a 16-channel amplifier ( $2 \mathrm{~kW}$ per channel) that can be spatially combined to $32 \mathrm{~kW}$ (30kW radially combined) of pulse power from 40-450MHz.

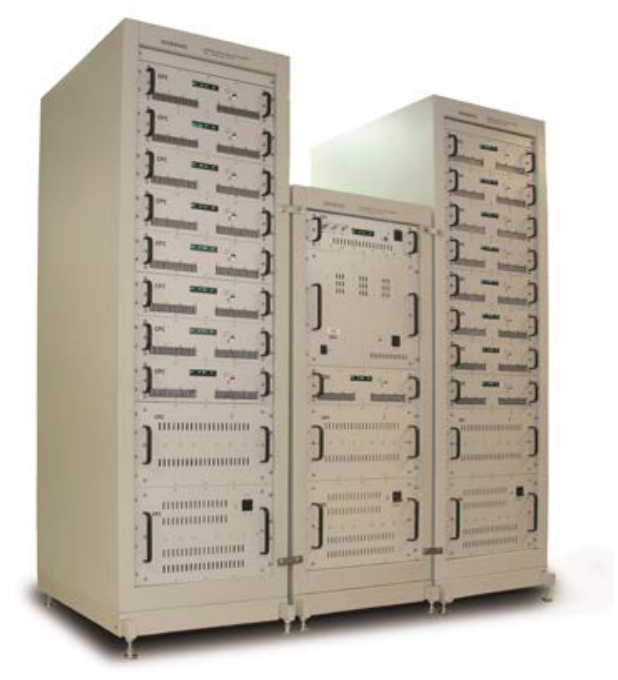

Fig. 5. 16 channel (2 kW per channel) PA for MRI applications. Courtesy of CPC.

Figure 6 shows a top-level block diagram of the system components. The RF input is fed to a 16channel RF matrix that takes one input signal, splits it into 16 separate signals and feeds them into a 16-channel phase/gain controller that can adjust the signal relative phase and amplitude of the RF power amplifiers to create a homogeneous RF B1 field. The phase/gain controllers are 8 
bit with a phase and amplitude resolution of 1.4 degrees and $-0.25 \mathrm{~dB}$ respectively. The phase/amplitude encoded signals are then sent to the 16-channel amplifier array.

Table 1 shows the general specification for the 10.5T amplifier system, with Fig. 7 showing test data plots of power and time domain for Gain/Phase Linearity and Pulse Fidelity, respectively. Human images produced at $7 \mathrm{~T}$ are shown in Fig. 8 (while the $10.5 \mathrm{~T}$ amplifier is complete, the 10.5 T magnet is still under construction at the University of Minnesota's Center for Magnetic Resonance Research CMRR).

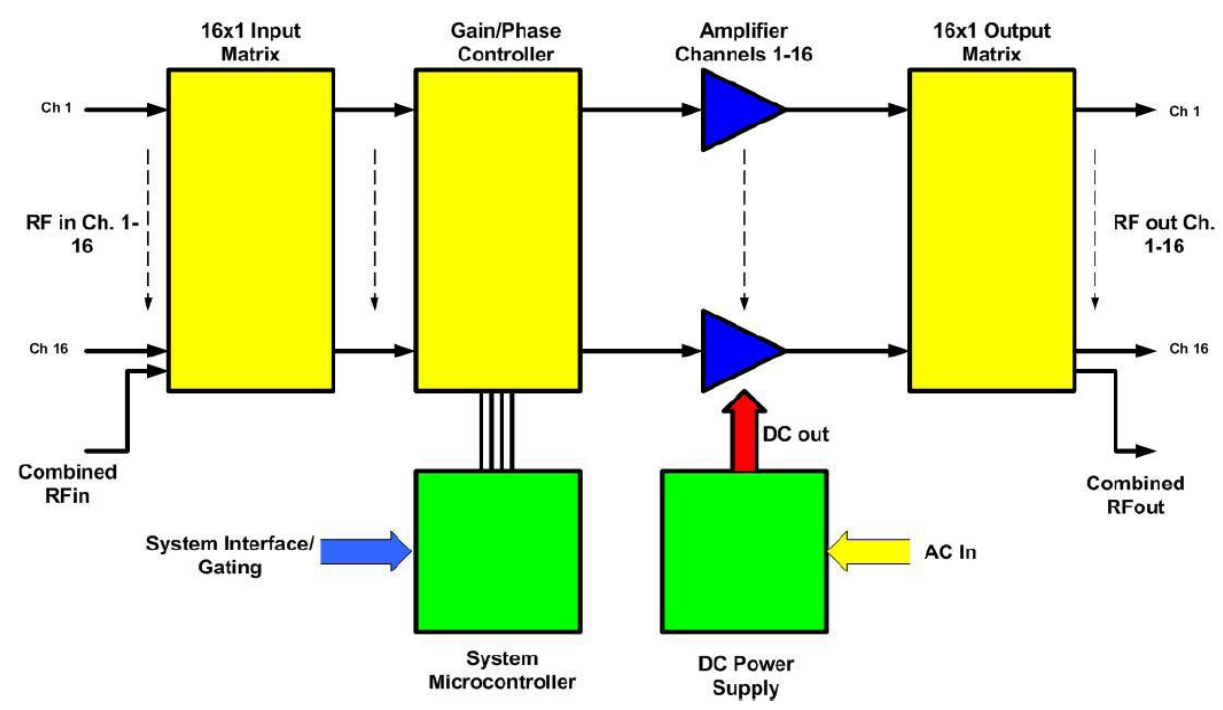

Fig. 6. 10.5T MRI amplifier block diagram.

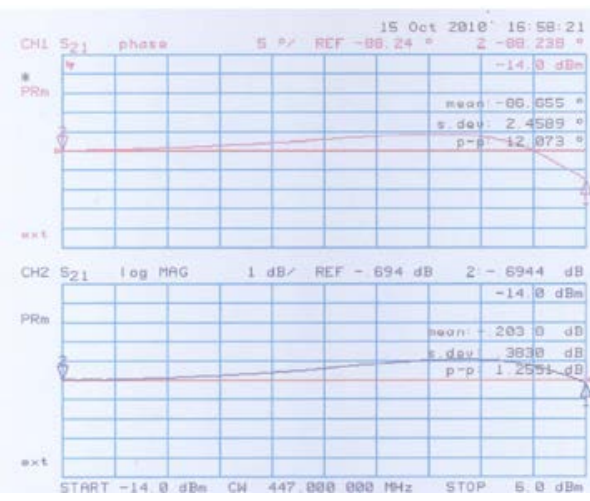

a

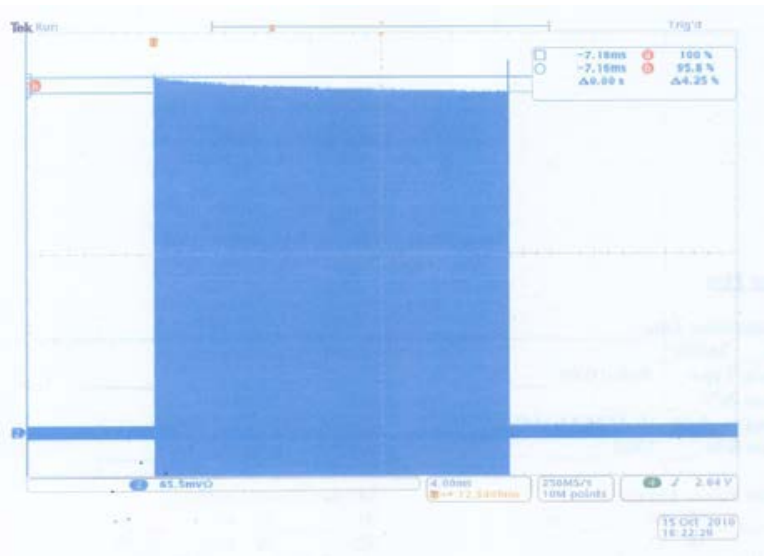

b

Fig. 7. a) Power Domain Performance $20-2$ kW (20 dB dynamic range), Phase Linearity: +/- 6 degrees (AM-PM Distortion) top plot; Gain Linearity: +/-0.6 dB (AM-AM Distortion) bottom plot; b) Time Domain Performance, Pulse Tilt: $4.25 \%$ @ 450MHz at 2kW across $20 \mathrm{msec}$ pulse width. 

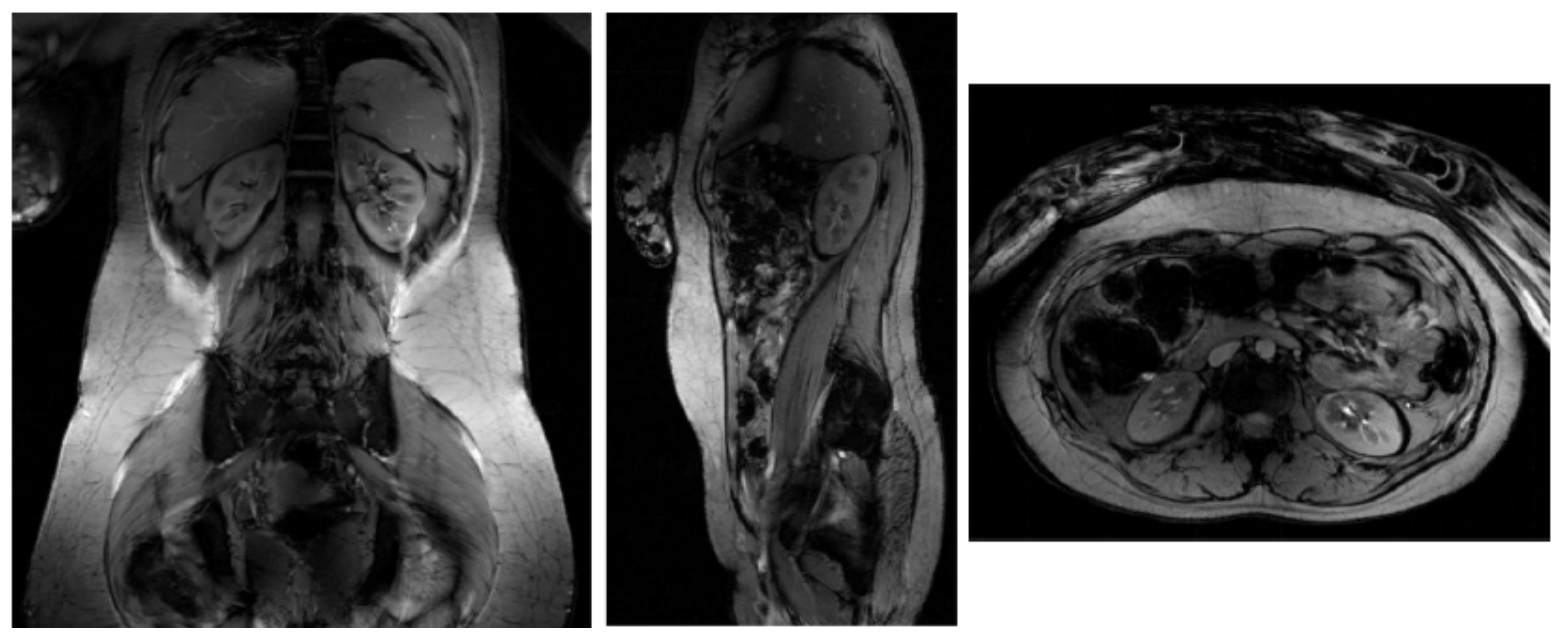

Fig. 8. 3 axis (sagittal, coronal and axial) 7T whole body scans (Scans courtesy CMRR, University of Minnesota, Dr. J Thomas Vaughan, Dr. Michael Garwood).

Another trend with MRI RF power amplifiers is "high field tolerant/compatible or in-bore" technology. This type of amplifier must be able to operate either adjacent to, or directly in the superconducting magnet bore. This requires the amplifier to function in strong fringe fields where hurdles include low noise output, EMI compatibility and low heat production. Amplifier classes of operation amenable to in field operation are class D/E switch- mode RF amplifiers because they offer low heat output. Advanced power domain error correction is required to correct for inherent transfer function anomalies. Fig. 9 shows field tolerant, RF power amplifiers mounted on the perimeter of a high field 16-channel TEM body coil for $7 \mathrm{~T}$.

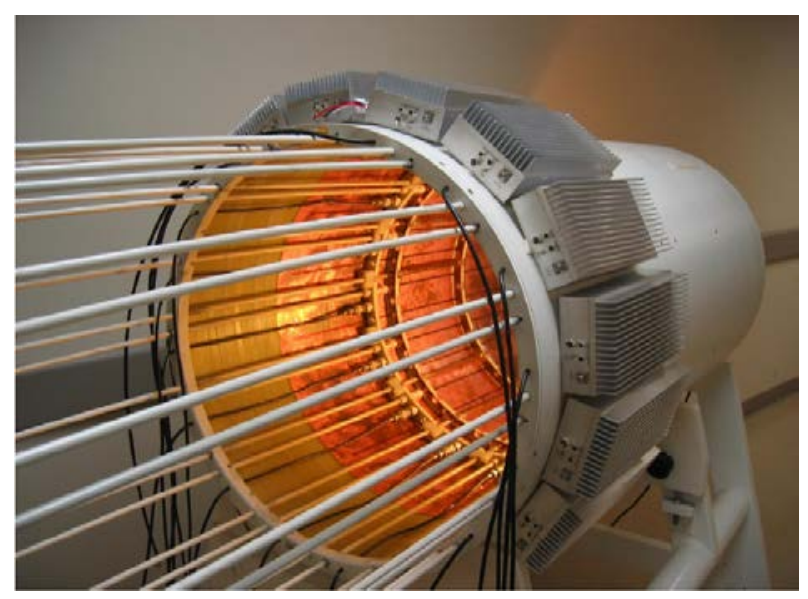

Fig. 9. Coil mounted, magnetic field tolerant, RF power amplifiers ,16 channels at $7 \mathrm{~T}$ (300MHz, $1 \mathrm{~kW}$ per channel. (TEM Coil Courtesy CMRR). 
For clinical grade MRI RF power amplifiers, solid-state technology has been gaining on tubes in terms of cost effectiveness and extended MTBF. This trend is expected to where tubes are ultimately supplanted. RF power amplifiers are used in a similar architecture with NMR spectrometers. NMR spectroscopy works on all the same principles as MRI; however, the technology is used to analyze chemicals and pharmaceuticals rather than human anatomy. Magnetic Resonance Spectroscopy (MRS) is a clever blend of anatomical imaging and spectroscopy that shows valuable metabolic information that can gauge the efficacy of chemotherapy at unprecedented speeds. Fig. 10 shows an example of MRS. The $4 \mathrm{~T}$ image is shown with spectroscopic data below the scan. While the image shows a qualitative view of a breast cancer tumor, the spectroscopy provides quantitative data on the choline concentrations within the tumor. Choline is a byproduct of angiogenesis (the formation of blood vessels within a tumor). The levels of choline concentrations are linked to tumor activity and monitoring this number may gauge whether or not a particular chemotherapy regimen is effective. The key advantage is this can be done within a relatively short time after the initial deployment of the drug. This research, while in its early stages, has shown promise.

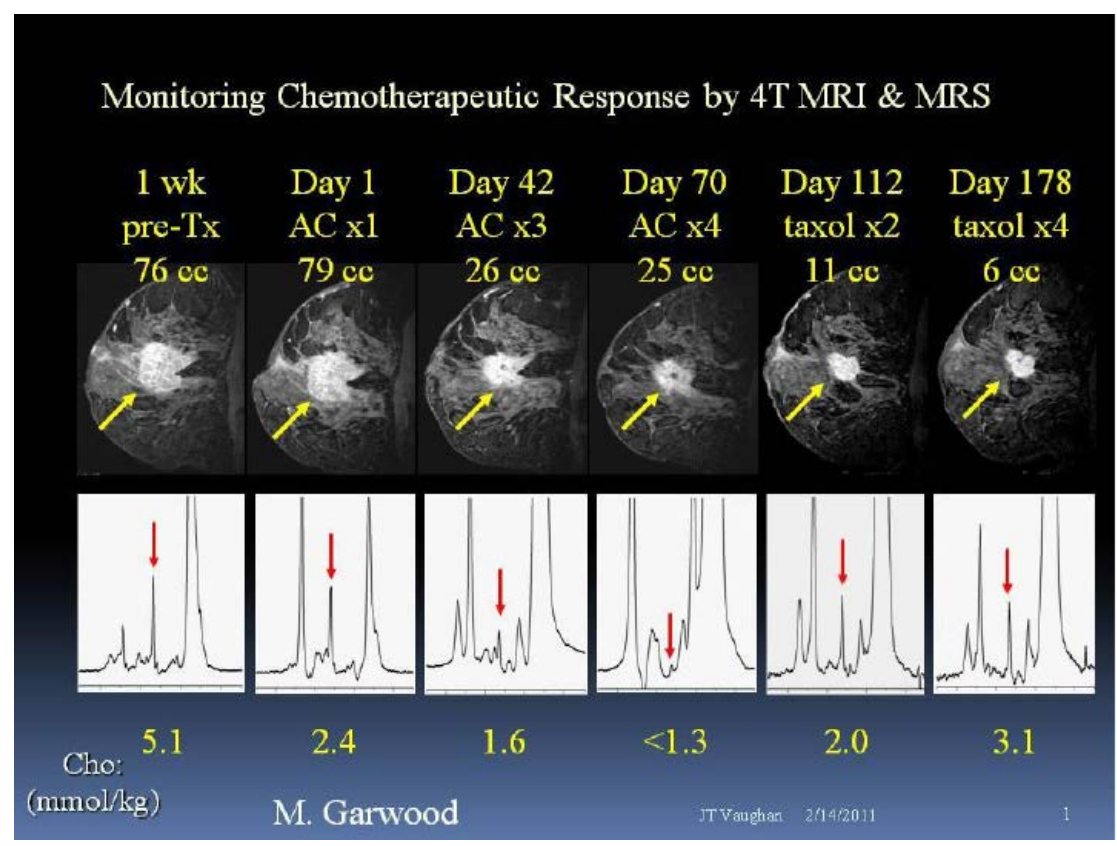

Fig. 10. Magnetic Resonance Spectroscopy (MRS) example at 4 Tesla (Scans courtesy CMRR, University of Minnesota, Dr. J Thomas Vaughan, Dr. Michael Garwood). 
Table 1. Typical 16-channel (2KW per channel) PA for MRI specifications. Data courtesy of CPC.

\begin{tabular}{|c|c|c|c|}
\hline Parameter & \begin{tabular}{|l|} 
Specification \\
(16ch)
\end{tabular} & Specification(combined) & Comments \\
\hline Frequency range (MHz) & $40-450$ & \multicolumn{2}{|l|}{$40-450$} \\
\hline Power output(pulse) (W) min. & 2000 & \multicolumn{2}{|l|}{30,000} \\
\hline Gain $(\mathrm{dB})$ & +63 & \multicolumn{2}{|l|}{+75} \\
\hline Gain flatness (+/-dB) & 3 & 3 & $6 \mathrm{~dB}$ p-p \\
\hline Input VSWR max & $2.0: 1$ & \multicolumn{2}{|l|}{$2.0: 1$} \\
\hline Harmonics,2nd ,3rd (-dBc) max & $-20,-12$ & \multicolumn{2}{|l|}{$-20,-12$} \\
\hline Spurious output (-dBc) max & -50 & -50 & Into 50 ohm load \\
\hline Noise output (blanked) max & $-154 \mathrm{dBm} / \mathrm{Hz}$ & \multicolumn{2}{|l|}{$-154 \mathrm{dBm} / \mathrm{Hz}$} \\
\hline Gain linearity $(+/-\mathrm{dB}) \max$ & 1 & 1.5 & 2 dB p-p per ch \\
\hline $\begin{array}{l}\text { Phase linearity (+/- degrees) } \\
\text { max }\end{array}$ & 7.5 & 7.5 & 15 degrees $\mathrm{p}-\mathrm{p}$ \\
\hline $\begin{array}{l}\text { Rising transition duration } \\
\text { (nsec) max }\end{array}$ & 150 & \multicolumn{2}{|l|}{150} \\
\hline Pulse tilt (\%) max & 8 & 8 & Absolute value \\
\hline $\begin{array}{l}\text { Falling transition duration } \\
\text { (nsec) max }\end{array}$ & 150 & \multicolumn{2}{|l|}{150} \\
\hline Pulse overshoot (\%) max & 10 & \multicolumn{2}{|l|}{10} \\
\hline Settling time (ns) max & 500 & \multicolumn{2}{|l|}{500} \\
\hline Un-blank delay (us) max & 2 & \multicolumn{2}{|l|}{2} \\
\hline Pulse width (ms) max & 20 & 20 & At full power \\
\hline Duty factor (\%) max & 10 & \multicolumn{2}{|l|}{10} \\
\hline Phase step resolution (degrees) & 1.4 & \multicolumn{2}{|l|}{1.4} \\
\hline Gain step resolution $(\mathrm{dB})$ & -0.25 & \multicolumn{2}{|l|}{-0.25} \\
\hline Phase shift time (us) max & 5 & \multicolumn{2}{|l|}{5} \\
\hline AC input (VACrms) & 208 & 208 & Single phase \\
\hline Operating temp(degC) & +10 to +40 & \multicolumn{2}{|l|}{+10 to +40} \\
\hline Interface & CAN & \multicolumn{2}{|l|}{ CAN } \\
\hline Size(HxWxD) inches & 78.14x71.5x33 & \multicolumn{2}{|l|}{$78.14 \times 71.5 \times 33$} \\
\hline
\end{tabular}


Particle Accelerators utilize power amplifiers to drive particles to near light speeds for medical isotope production/cancer treatment and various topics in basic research. As with the device trend in MRI, at power levels below 250kW, transistors are now being considered as tube alternatives as they have better reliability, graceful degradation ( a failure of one transistor does not shut down an entire system) and improved phase stability. Sites with solid-state amplifiers in excess of $200 \mathrm{~kW}$ are now in operation [12]. Table 2 shows performance specifications for a typical commercial accelerator-class RF power amplifier.

Table 2. Typical Particle Accelerator Class Amplifier Specifications. Data courtesy of CPC.

\begin{tabular}{|c|c|}
\hline Operating Frequency & $200+/-1 \mathrm{MHz}$ \\
\hline Pulse Power into 50 Ohms & $7000 \mathrm{~W}$ (min) \\
\hline Pulse Width & 2.5 msec max. \\
\hline Linearity (+/- $1.5 \mathrm{~dB}$, Class $\mathrm{AB})$ & $7000 \mathrm{~W}$ (min) \\
\hline Gain (0 dBm input) & $+67 \mathrm{~dB}$ (nominal) \\
\hline Gain Flatness & +/- 1 dB, typ. \\
\hline Harmonic Content $\left(2^{\text {nd }} / 3^{\text {rd }}\right)$ & $-20 \mathrm{~dB} /-12 \mathrm{dBc}$, typ. \\
\hline Input/Output Impedance & 50 Ohms (nominal) \\
\hline Input VSWR & Less than $2: 1$ \\
\hline Duty cycle & $20 \%(\max )$ \\
\hline Amplitude rise/fall time & 350 ns, typ. \\
\hline Amplitude Droop & $5 \%$ max. \\
\hline Phase change/output power & $12^{\circ}$ to rated power, typ. $25^{\circ}$ max. \\
\hline Phase error overpulse & $5^{\circ}$ to $2.5 \mathrm{~ms}$ duration, typ \\
\hline Noise figure & 12 dB typ. \\
\hline Output noise (blanked) & $20 \mathrm{~dB}$ over thermal, typ. \\
\hline Blanking delay & 1 us, typ. on/off, TTL signal \\
\hline Pulse overshoot & $5 \% \max$. \\
\hline
\end{tabular}


In particle accelerators for high-energy research, multiple superconducting cavities are used with the cavity dimensions governing the frequency of operation, often at frequencies below $1000 \mathrm{MHz}$. In Europe, for example, one experiment of the SOLEIL synchrotron operates at $352 \mathrm{MHz}$ and requires a boost amplifier of $35 \mathrm{~kW}$ of $\mathrm{CW}$ power, obtained using the combined output of a number of $330 \mathrm{~W}$ solid-state power amplifier modules (Fig. 11) [12]. Special monitoring systems as well as water-cooling are required at this power level. The amplifier must also have high reliability, be unconditionally stable and be able tolerate large load mismatches [12].

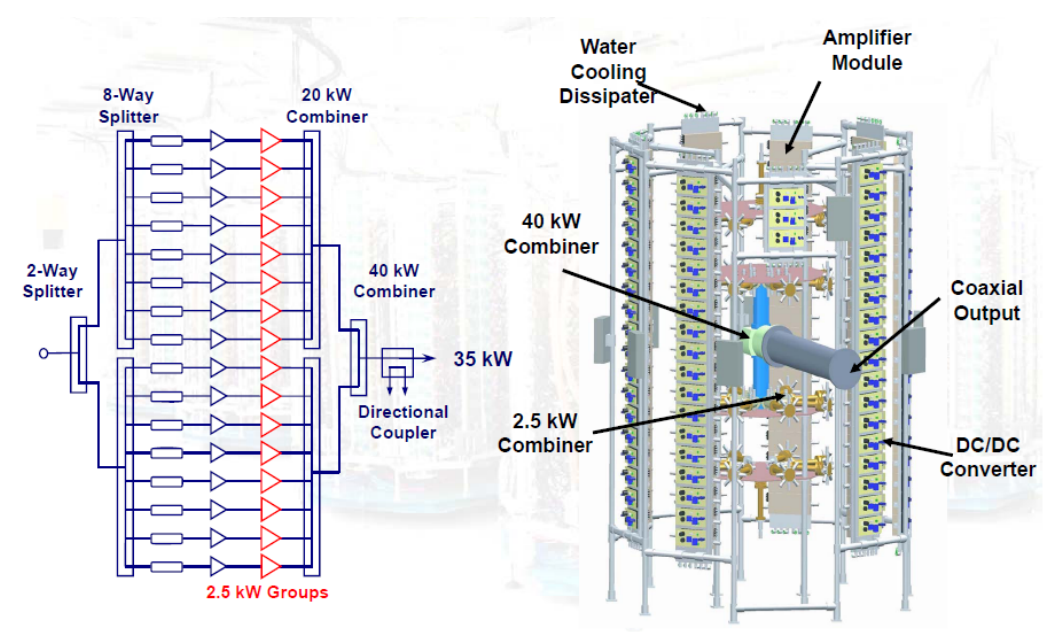

Fig 11. Schematic diagram of combined 35 kW 352 MHz PA for SOLEIL. Used with permission.

Using the same concept, higher powers have been obtained at the $200 \mathrm{~kW}$ level for the storage ring (Fig. 12).

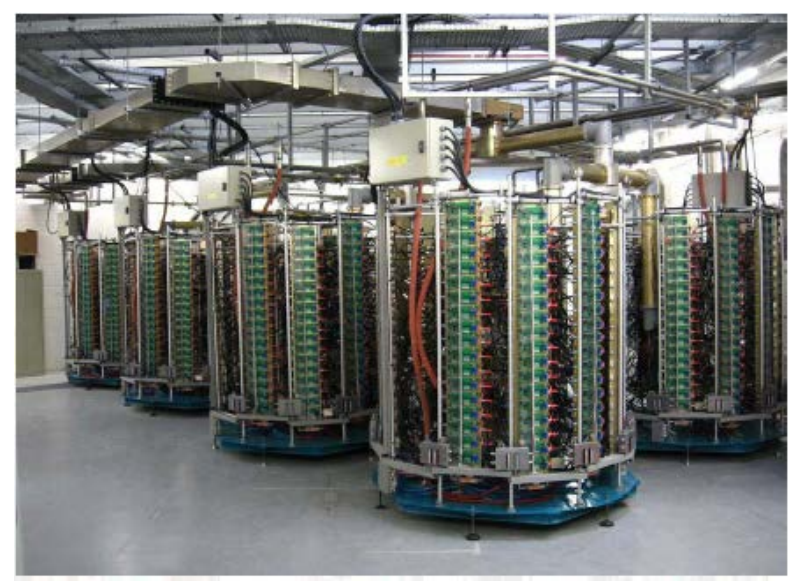

Fig. 12. 5-tower array of $40 \mathrm{~kW}$ per tower, $200 \mathrm{~kW}$ total CW power. Used with permission.

Of particular interest is the combiner used to obtain tens of $\mathrm{kW}$ of power from a large array of lower power PA modules. An example of a 160-way RF power combiner is shown in Fig. 13. 


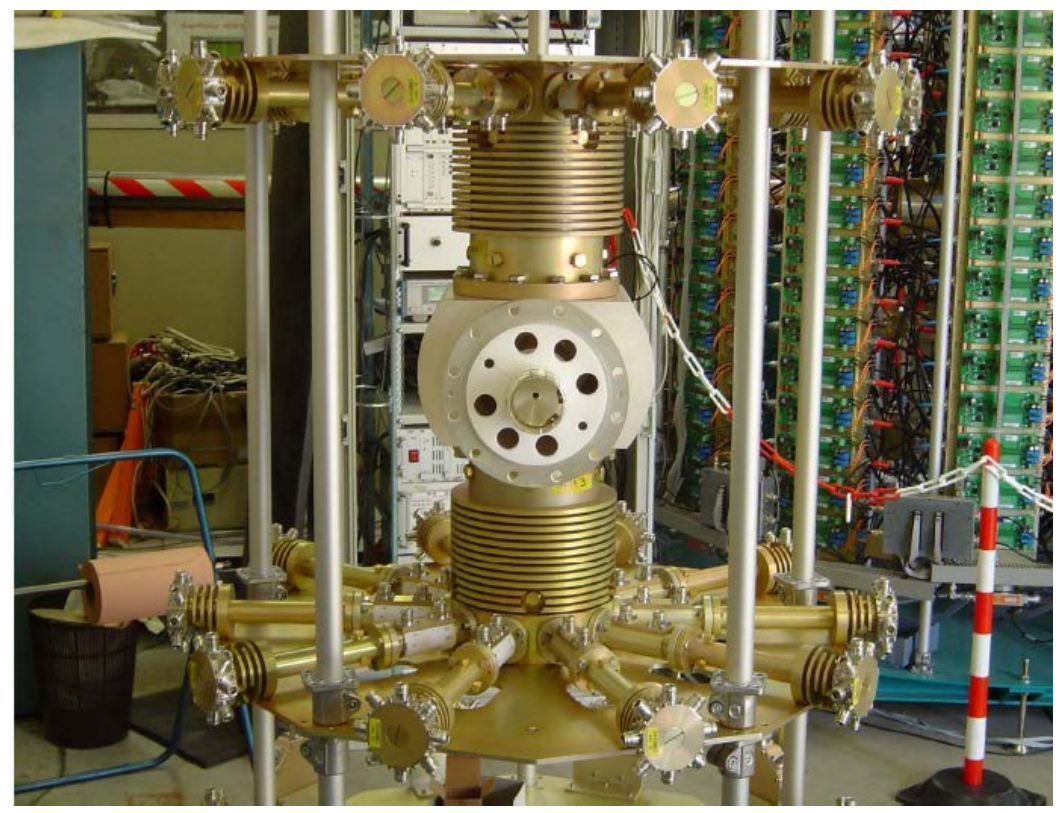

Fig. 13. 160-way RF power combiner for the SOLEIL project. Used with permission. 


\section{DC-DC CONVERTERS}

DC-DC converters are essential for a wide range of applications such as switch-mode power supplies, hybrid/electric vehicles, uninterruptible power supplies, motor drives, and interfacing renewable energy sources to the utility grid [13-20]. Pulse-width modulated (PWM) DC-DC converters have been the most common converter scheme because of their high efficiency and small size due to the switching operation of the power devices. High efficiency and high switching frequency permit the use of smaller, lighter, and cheaper power devices, heat sinks, as well as magnetic and filter components. This in turn, results in a smaller converter with a high power density, which is desirable in many practical applications. This section provides an overview of two major classes of DC-DC converters: the conventional low switching frequency DC-DC converter and a newer application for frequencies well into the UHF band. Other types of converters not covered in the section are Synchronous DC-DC Converters, Bidirectional DC-DC Converters and Tapped-Inductor DC-DC Converters; the interested reader is invited to explore references on these more advanced topics [16-20].

\section{A. Conventional DC-DC Converters}

Fig. 14(a)-(c) shows the basic dc-dc converter topologies, namely, buck (step-down), boost (step-up), and buck-boost (step-up and down) converters [15]. The main components in the converters are a controllable switch (such as a MOSFET or an IGBT at low switching frequencies and GaN-based FETs for high frequencies) as the primary switch, a free-wheeling diode as the secondary switch, an inductor, and a filter capacitor. The conversion ratio of the converter is determined by the duty cycle of the switch. Power devices operated as switches result in low conduction losses, however, they introduce switching losses. Conduction losses include losses due to the on- time resistance of the switch as well as the forward voltage drop and the on-time resistance of the diode. Switching losses are due to the charging and discharging of the parasitic capacitances of the switches and the reverse-recovery of the diode during the switching transitions. Also, by increasing the switching frequency, magnetic and filter component sizes can be reduced and thereby, losses due to the inductor and capacitor equivalent series resistances (ESRs) can be minimized. However, the switching losses in the devices restrict the operation of PWM converters to low switching frequencies, typically to hundreds of $\mathrm{kHz}$. By employing soft-switching techniques, zero- voltage switching or zero-current switching, the switching frequency of DC-DC converters can be increased up to tens of $\mathrm{MHz}$.

In applications such as switch-mode power supplies, galvanic isolation is needed between the input and output. Transformer derived DC-DC converter topologies are suitable for this. Fig. 14 (d) and (e) show the buck derived forward converter and the buck-boost derived flyback converter, respectively. The transformers in these converters are operating at frequencies much higher than $60 \mathrm{~Hz}$, and so are much smaller than typical line transformers. 


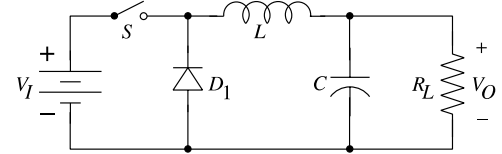

(a) Buck converter

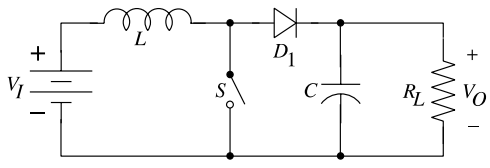

(b) Boost converter

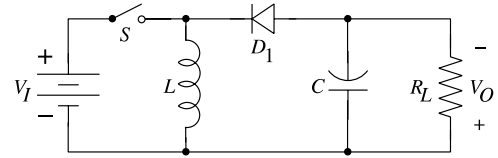

(c) Boost converter

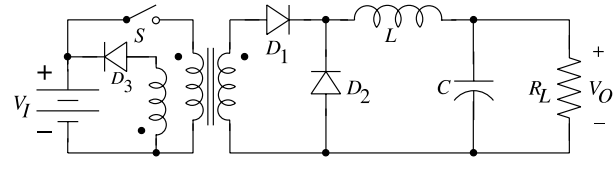

(d) Forward converter

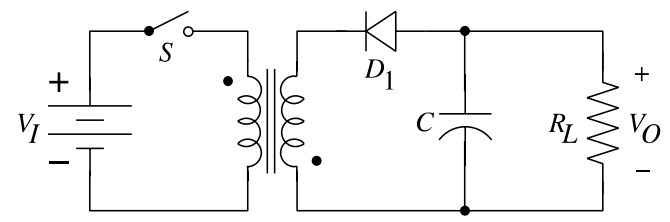

(e) Flyback converter

Fig. 14. Some examples of non-isolated and isolated DC-DC converter topologies: a) buck converter; b) boost converter; c) boost converter; d) forward converter; and e) flyback converter.

\section{B. High frequency DC-DC Converters}

Envelope tracking (ET) envelope elimination and restoration (EER), and hybrid ET/EER architectures [21-23] have become a viable alternative for efficiently and linearly transmitting modern digitally-modulated signals. With amplitude or envelope components of hundreds of $\mathrm{MHz}$, fast DC/DC power converters are needed in the envelope modulator, the block responsible for providing a dynamic biasing voltage to the RF power amplifier (PA). This is the main reason why a linear amplifier is often used in conjunction with a high-efficiency switched-mode power converter (SMPC) resulting in a hybrid split-band [24, 25] or a feedback [26, 27] topology. In order to further improve the dynamic response of the SMPC, classic PWM DC/DC converters operating at hundreds of $\mathrm{MHz}[28,29]$ and resonant topologies switching in the UHF or lower microwave bands [30, 31] have been proposed. With the introduction of GaN HEMT devices over the last ten years, the low $\mathrm{R}_{\text {on }} * \mathrm{C}_{\text {out }}$ product (ON-state resistance times the output capacitance) together with a very high breakdown voltage have helped power this new technology. One example of a high frequency converter is the double class $\mathrm{E}$ or class $\mathrm{E}^{2}$ topology [32, 33] that integrates a class E inverter with a class E rectifier (Fig. 15). Zero voltage and zero voltage derivative switching conditions, ZVS and ZVDS, are forced in both circuit parts in order to minimize the impact of the frequency dependent switching loss mechanisms [34, 35]. 
At UHF and beyond, fast Schottky diodes capable of handling the high current and voltage levels are rarely available and so high current/high voltage tolerance transistors such as GaN are employed [36].

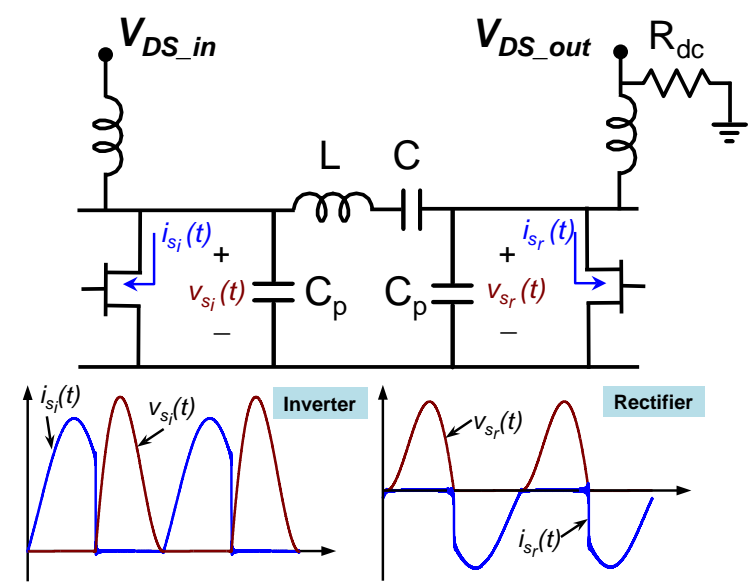

Fig. 15. Class $E^{2}$ DC/DC synchronous converter (a class $E$ inverter plus an active class $E$ rectifier). The ZVS and ZVDS waveforms are included.

If the frequency is high enough that the simple LC network is inappropriate due to undesired parasitics, two alternatives may be employed: a multi-resonant or poly-harmonic network (Fig. 16a) or a self-resonant coil-based network (Fig16.b). In the first case, the open circuit conditions at the most relevant harmonics (third and second) together with the nominal impedance value at the fundamental [36] are synthesized by following a lumped-element version of the widely known microwave transmission line topology suggested in [37]. For the latter approach, a high Q coil, self-resonant between the second and third harmonics [38], is introduced to approximate an open circuit termination, while combined with capacitors to force the desired impedance to the fundamental. While the second technique provides only a rough approximation to class E operation, it may result in a more compact solution. Examples of these techniques using packaged and die Cree GaN devices are shown in Fig. 17. Large-signal bandwidth and slew-rate values as high as $51 \mathrm{MHz}$ and $1.37 \mathrm{~V} / \mathrm{nS}$, respectively, have been measured for the converter in Fig. 17b. Power electronics specialists in search of increased power density $\left(\mathrm{W} / \mathrm{cm}^{2}\right)$ are very interested in these high frequency approaches. 


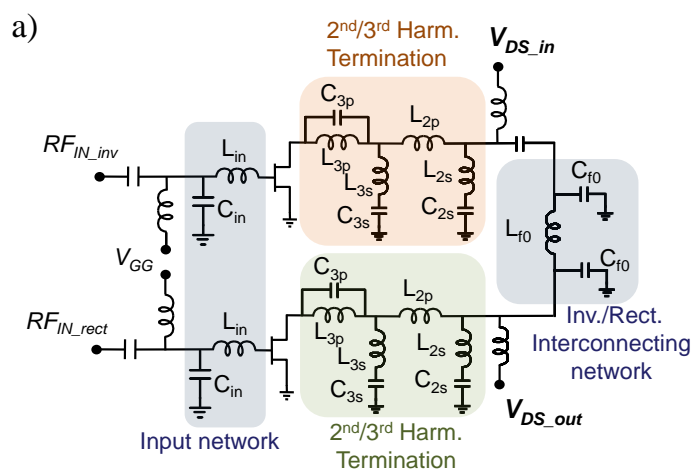

b)

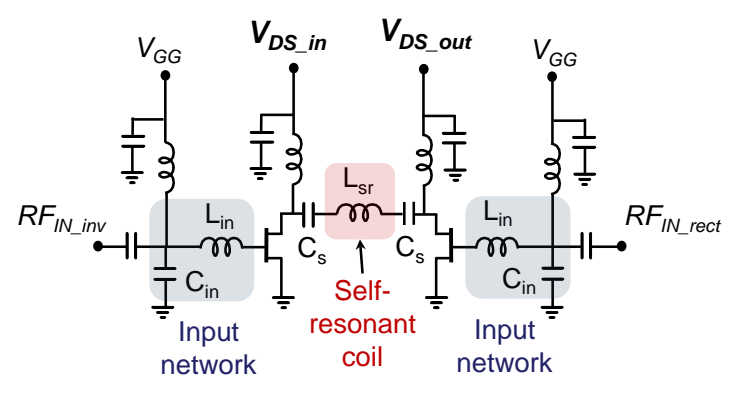

Fig. 16. Schematics of UHF Class $E^{2}$ converters using the a) poly-harmonic impedance synthesizing approach and b) the self-resonant coil-based network.

a)

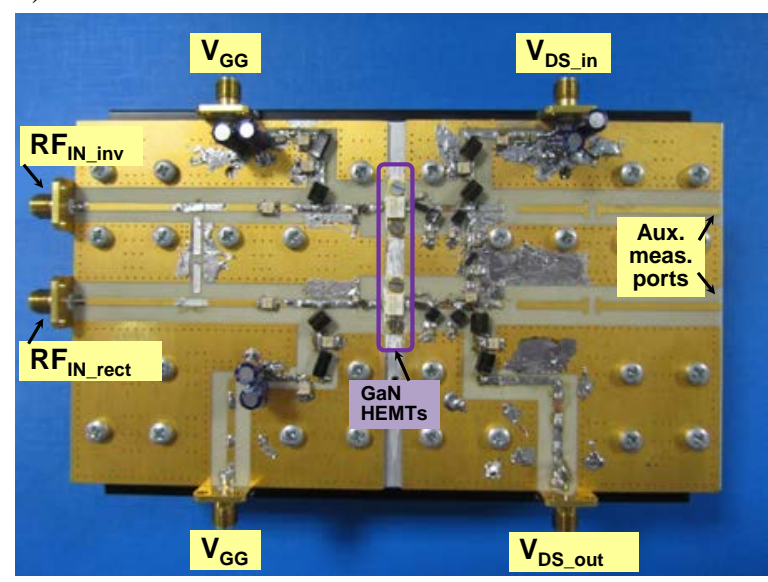

b)

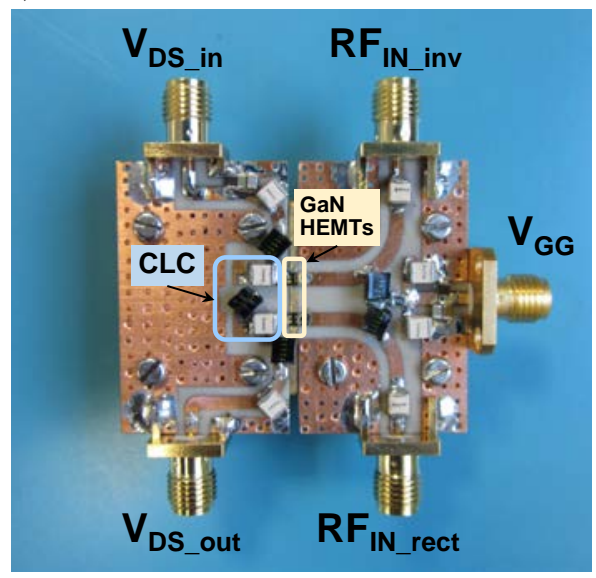

Fig. 17. Photographs with implementation details of the GaN HEMT-based UHF DC/DC converters. The design frequencies are a) $780 \mathrm{MHz}$ [30] and b) $1 \mathrm{GHz}$ [39]. 


\section{RECEIVERS}

For more than eight decades, the superheterodyne ('superhet') was the standard receiver architecture. The superhet receiver takes the input signal, moderately it by approximately $20 \mathrm{~dB}$ at the input signal frequency and then frequency shifts it to an intermediate frequency (IF) using mixer and local oscillator circuitry. (More than one frequency shift may take place depending on the band-plan and filtering requirements.) The resulting IF signal is heavily amplified by 80 $\mathrm{dB}$ or more, usually at a lower frequency. The choice of final IF is based on a combination of factors including location of other users in the frequency spectrum, availability of appropriate circuit technology and the "1/10" rule of thumb (IF should be approximately 1/10 the input signal frequency) [1]. The use of a high frequency IF reduces negative effects such as $1 / \mathrm{f}$ noise and the need for interstage DC coupling. While the superhet is a complex receiver architecture, it is still the architecture of choice for high performance, wide dynamic range receivers.

An alternative receiver architecture developed as a potential competitor to the superhet was the homodyne or direct conversion (D-C) receiver. Popular with radio amateurs since the 1960s for lightweight, simple circuitry and low-cost battery-operated portable transceivers, D-C has now become the architecture of choice for cellular-handset designers. D-C is a "zero-IF" or "near-zero-IF" method, where elimination of the IF amplifier and filter reduces size and cost. Signal selection occurs at baseband, and most of the gain follows the baseband selectivity. A true zero-IF system translates the carrier to zero Hz, creating a DC value that must have its effects eliminated to avoid threshold shifts in succeeding signal processing stages, e.g. analog-to-digital converters (ADCs), and perhaps an associated driver amplifier. Near-zero-IF addresses this issue with an IF in the tens of $\mathrm{kHz}$ range that can be implemented digitally in the following DSP stages. Nearly all D-C systems are designed to provide in-phase and quadrature (I-Q) outputs, which are immediately digitized. All baseband processing, including filtering and demodulation, is achieved digitally.

The use of direct-sampling techniques in receivers is growing rapidly. In these systems, minimal signal processing is implemented ahead of the ADC, typically limited to low noise amplification and bandpass filtering, and perhaps notch filters for interference reduction. The broadband input allows the receiver to simultaneously detect and demodulate signals at many different frequencies. The range of frequencies is limited by the bandwidth of the ADC, but over this range, direct-sampling can provide a continuous observation of the entire RF spectrum. Signal processing techniques include digital downconversion (decimation), I-Q demodulation, FFT time-to-frequency domain conversion, and many other DSP functions. Continued improvement in ADC input dynamic range and resolution (number of bits) is the primary performance driver for this developing technology. 


\section{ELECTROMAGNETIC COMPATIBILITY (EMC)}

RF circuit designers have always needed a working knowledge of electromagnetic interference / electromagnetic compatibility (EMI/EMC) techniques in order to avoid unwelcome problems associated with the control of RF coupling between circuits and systems. Starting with the early days of vacuum tubes, techniques for EMI/EMC mitigation have continued to evolve along with RF technology. In the days of vacuum tubes, high voltages and low currents were the rule; today, lower voltage and higher currents dominate transistor-based circuits. The impedance differences in these two circuit types influence the type and level of RF coupling that occurs. An EMI problem consists of three components: source, coupling path and victim circuit. It can be mitigated by attacking any one or all three of these components. The coupling mechanism can be one of four types: (1) conducted (via a shared impedance between circuits), (2) electric field coupling in the near-field (i.e., capacitive coupling), (3) magnetic field coupling in the near-field (i.e., inductive coupling), or (4) far-field coupling. The four types of coupling exhibit different frequency responses and these differences will be discussed in this section.

\section{Capacitive Coupling}

During the vacuum tube era, circuits operated at high voltages and low currents. The primary coupling mechanism for these high-impedance circuits is electric field coupling in the near-field. A simplified analysis for capacitive coupling using the equivalent circuit shown in Fig. 18 can be performed by studying two wires positioned above a ground-plane [40]. This circuit can be analyzed for the unwanted coupling from source wire \#1 to victim wire \#2. The undesired coupled voltage (in EMC parlance the 'noise' voltage, $V N$ ) on the victim wire using the equivalent circuit in Fig. 18a results in the VN frequency response shown in Fig. 18b, where $R=R S 2|| R L 2$.
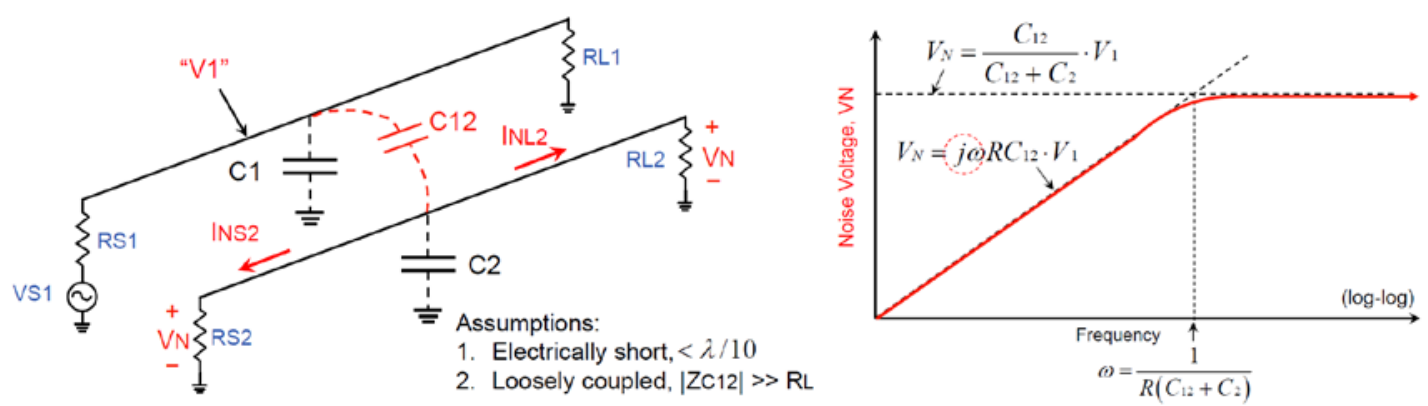

Fig. 18. a) Capacitive coupling between two wires suspended over a ground-plane with stray capacitances $C 1, C 2$, and C12. The noise voltage has the same magnitude and polarity at both ends of the victim wire; b) Bode plot of undesired capacitive coupling between the two wires. 
Although the coupling does not increase above the break frequency, $\omega$, the coupling often needs to be reduced. The wires (or circuits) can be separated to reduce C12, or the circuit resistance, $R$, can be reduced, but these modifications are often inadequate. Shielding is needed as shown in Fig. 19. For example, a bayonet-lock metal tube cover (a Faraday shield) was often used to isolate vacuum tube circuits from one another and prevent multi-stage oscillation.

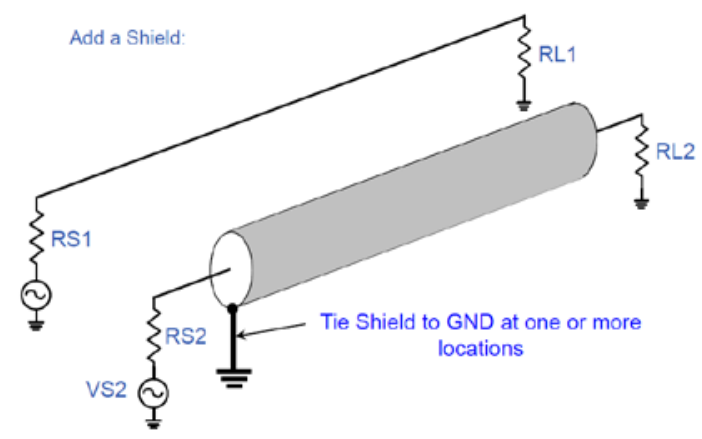

Fig. 19. Elimination of capacitive coupling between two wires suspended over a ground-plane. If the shield is tied to ground at one or more locations, it will completely eliminate the capacitive coupling (ignoring pig tail effects).

\section{Inductive Coupling}

The solid-state revolution replaced virtually all vacuum tube circuits and ushered in low-voltage circuitry operating at low to moderate currents. The coupling mechanism for these lowimpedance circuits is primarily magnetic field coupling in the near-field. A simplified equivalent circuit for this inductive coupling is shown Fig. 20a with the corresponding voltage induced in the victim wire by Faraday's Law, causing a current to flow $\left(\mathrm{I}_{2}\right)$ as shown in Fig. 20b [40].

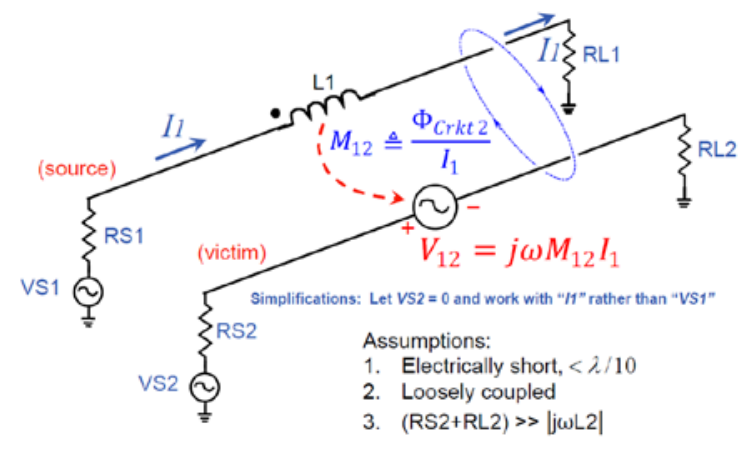

a

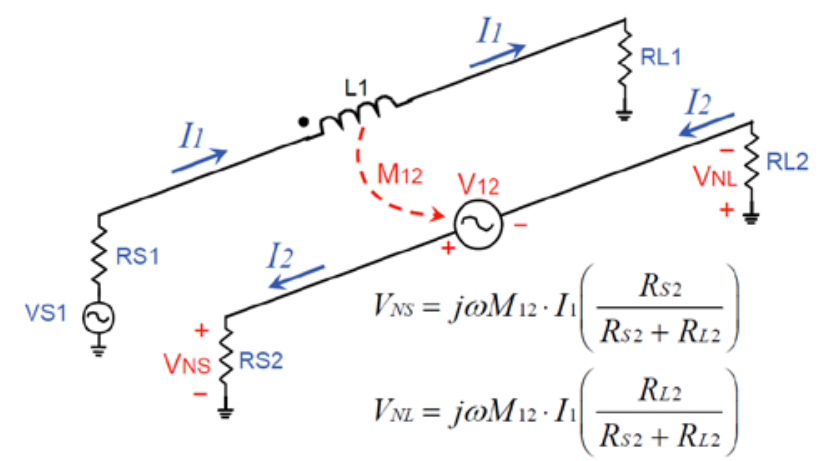

b

Fig. 20 a) Inductive coupling between two wires suspended over a ground-plane with wire inductances $L 1, L 2$, and mutual inductance M12. A voltage, V12, is induced in the victim wire by Faraday's Law; b) Inductive coupling between two wires suspended over a ground-plane. The induced noise voltages have the opposite polarity at the ends of the victim wire. 
When analyzed for unwanted coupling from source wire \#1 to victim wire \#2, the noise voltage on the victim wire can calculated as $j \omega M_{1 \mathbf{z}} I_{\mathbf{1}}$. In contrast to the capacitive coupling case, the coupling continues to increase without encountering a break frequency. The circuitry can be separated to reduce $M 12$, but this modification is often inadequate and shielding is required. The circuit shown in Fig. 21a can be analyzed to determine the effect of adding a shield [40]. The result is plotted in Fig. 21b.

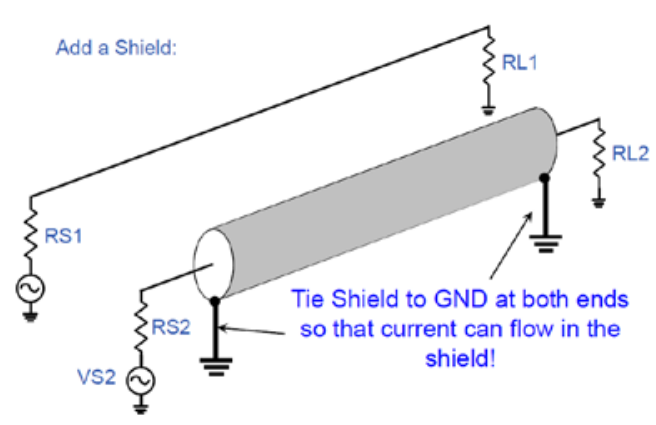

a

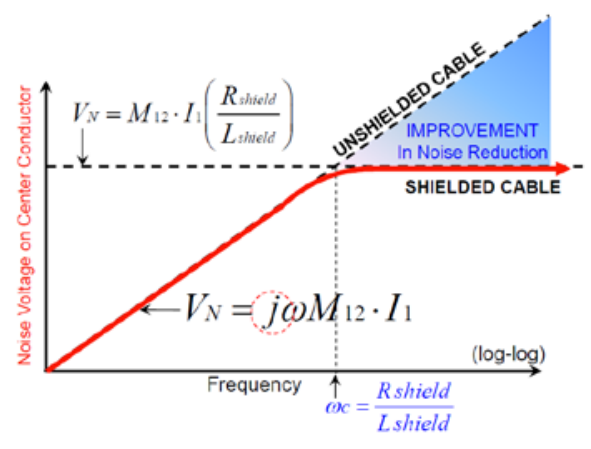

b

Fig. 21. a) Reduction of inductive coupling between two wires suspended over a ground-plane. The shield must be tied at both ends or it will have no effect whatsoever on magnetic field coupling; b) Bode plot of undesired inductive coupling between the two wires shown in Fig. 20 with one shield added.

When a shield is added, the coupling amplitude encounters a breakpoint at Rshield/Lshield and does not increase further. Rshield is the resistance of the shield, but it should be emphasized that Lshield is not the inductance usually associated with a coaxial cable. High frequency RF currents flow on the outside surface of the inner conductor and return on the inside surface of the shield. The mutual inductance between the inner conductor and the shield is negative and this cancels most of the self-inductance of the two conductors. The shield voltage induced by the source circuit causes a current to flow on the outside surface of the shield as if it were merely a thick wire. This current flows on the shield and returns on the ground-plane directly beneath it. The self-inductance of this path defines the value for Lshield, and it increases if the coaxial cable is contorted into a coiled-shape.

A further reduction in inductive coupling can be achieved if both the source and the victim wires are shielded. The resulting improvement is illustrated in Fig. 22a. The improvement can be quantified versus frequency as shown in Fig. 22b. 


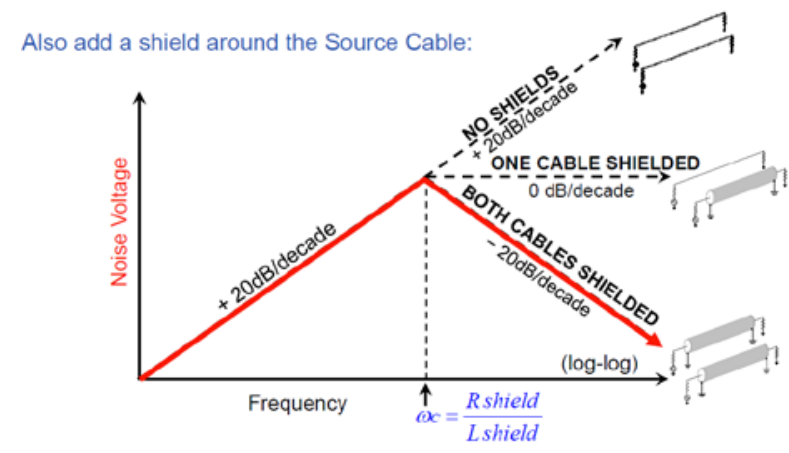

$\mathrm{a}$

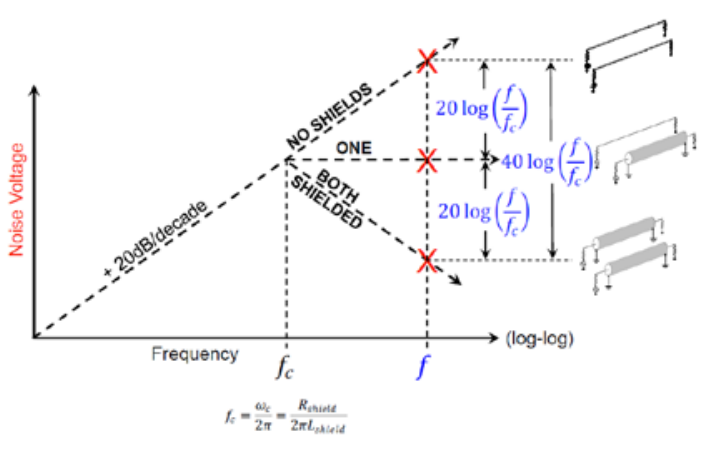

$\mathrm{b}$

Fig. 22. a) Bode plot of undesired inductive coupling between the two wires shown in Fig. 24a with two shields added; b) noise voltage versus frequency in $\mathrm{Hz}$ for inductive coupling between the two wires shown in Fig. 24b.

\section{Far-Field Coupling}

Far-field coupling becomes dominant at frequencies in the VHF range and higher, and different rules apply for achieving high levels of RF isolation between shielded enclosures. It is possible to achieve very high isolation, well in excess of $150 \mathrm{~dB}$, but if any coupling path is neglected, the isolation is compromised and lowers to only about 20 to $30 \mathrm{~dB}$ better than having no shielding at all [41]. Undesired energy can get into a shielded enclosure in several ways:

(1) RF energy can radiate directly into the enclosure via air holes, seams and gaps,

(2) RF energy can conduct into the enclosure via RF currents flowing on the outside surface of shielded cables that enter the enclosure, and

(3) RF energy can conduct into the enclosure via RF currents flowing on the outside surface of any wires (power feed and $\mathrm{I} / \mathrm{O}$ ) that enter the enclosure.

All of these mechanisms must be addressed to avoid RF Interference (RFI) problems. The following paragraph outlines some approaches in reducing far-field coupling to improve RF isolation.

With the exception of low-frequency magnetic fields, the thickness of the metal enclosure is not important from an electrical standpoint; anything thick enough to be mechanically rigid is adequate. Unsealed gaps are not acceptable. Air holes should be kept small in diameter [40]. RF bulkhead connectors must be used for all RF inputs and outputs. The bulkhead connectors must make a snug $360^{\circ}$ perimeter bond where they pass through the enclosure wall (the EMC Barrier). 
This prevents RFI currents from flowing into the shielded enclosure on the outside surfaces of the coaxial shields. The power feed and all I/O lines must pass through suitable feed-through capacitor filtering. Pi-filtered EMI connectors are preferred, and the metal shell of the EMI connector must make a $360^{\circ}$ perimeter bond where it passes through the metal enclosure wall. The feed-through capacitor strips off RF currents that would otherwise flow into the shielded enclosure on the wires. These currents are constrained to the outside surface of the enclosure and return back to their origin via displacement currents. (These currents cannot make it into the interior surface of the enclosure.) If the I/O cannot tolerate the capacitive loading of an EMI connector, consideration should be given to using a fiber optic (non-metallic) connection scheme. If metal water pipes are used for cooling, they must also make a $360^{\circ}$ perimeter electrical bond where they pass through the enclosure wall. (They are treated just like RF connections in order to keep RF currents from flowing into the shielded enclosure via the outside surfaces of the pipes). The equivalent of the double-compartment filtering shown in Fig. 23a and 23b can be achieved by using an EMI pi-filter as illustrated in Fig. 23c.

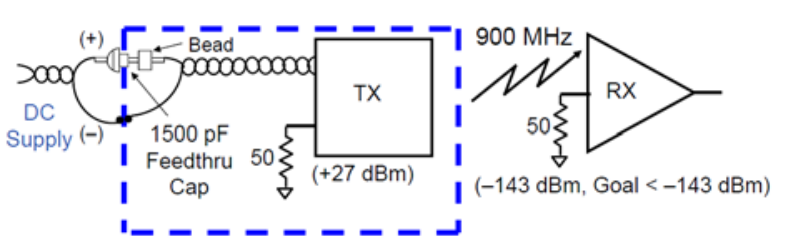

a

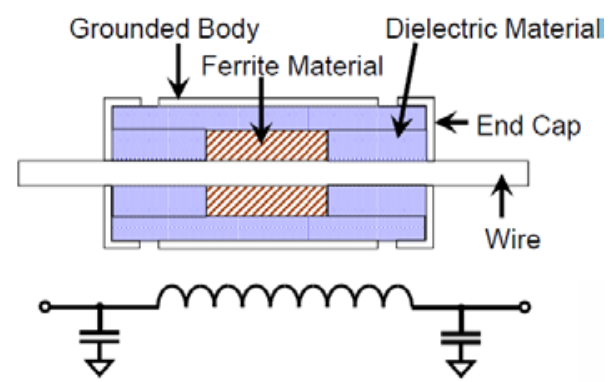

C

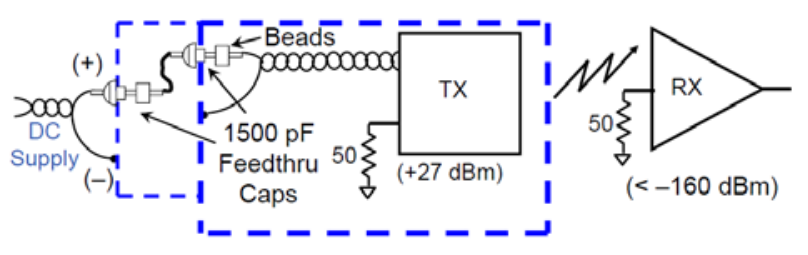

b

Fig. 23. a) Example of RF isolation achieved between a transmitter and a receiver operating on the same carrier frequency at $900 \mathrm{MHz}$ and separated by a few inches from each other. A single DC feedthrough capacitor is used to achieve a total RF isolation of $170 \mathrm{~dB}$ from TX output to RX input; b) Example of RF isolation achieved between a transmitter and a receiver operating on the same carrier frequency at $900 \mathrm{MHz}$ and separated by a few inches from each other. C) Illustration of EMI pi-filter. The grounded body must make a 360 degree perimeter bond to the enclosure wall where it passes through the wall (the EMC barrier).. Double-compartmented filtering of the DC feed is used to achieve a total RF isolation of more than $187 \mathrm{~dB}$ from TX output to RX input. (The measurement was test equipment limited.) [41] 


\section{BROADCASTING (BC)}

Broadcasting (BC) is the one-way delivery of information via radio frequencies to a multitude of listeners and viewers (as opposed to one-way content delivery via the Internet using streaming technology). The first known broadcast was by R. Fessenden on Christmas Eve, 1906 to ships in the Boston, MA harbor, with KDKA in Pittsburgh, PA being the first commercial broadcast station in 1920. A BC transmitter includes the power amplifier and antenna system, and is often linked to the studio by cable or microwave link, The antenna is usually located on a site that affords wide area coverage. More recent BC systems use satellites with satellite radio music stations being the most common.

\section{A. AM BC}

The AM radio broadcast band is available worldwide (530-1710 kHz in the U.S.)with typically a $5 \mathrm{kHz}$ modulation bandwidth. Transmit powers range from 1 to $50 \mathrm{~kW}$ with up to $100 \mathrm{~km}$ ground wave coverage during the day. So-called "clear-channel” stations provide regional and even continental coverage at night via ionospheric reflection [1]. In the U.S., AM stereo can be transmitted by using left/right signals multiplexed using phase modulation. Transmitters employing pulse-step amplitude modulators and multiple $5 \mathrm{~kW}$ class-D RF PAs with high efficiency switching transistors and power combiners can achieve transmit efficiencies of $70 \%$ or more.

AM radio stations in the U.S. may have digital ("HD Radio") transmission in addition to the standard analog channel. AM HD Radio provides audio quality approximately equal to standard analog FM transmission. The only FCC-approved method uses a system developed by iBiquity Digital Corporation, which places the digital signal in sidebands above and below the existing AM carrier frequency. The digital signal consists of multiple OFDM (Orthogonal Frequency Division Multiplex) subcarriers, with transmitted waveforms designed so digital emissions fall within the spectral emission mask of the AM channel. Digital AM transmission carries the same programming via both analog and digital modes. Receivers automatically revert to the analog channel when low signal strength or interference prevents detection of the digital signal.

\section{B. Longwave BC}

In the U.K. and Africa (ITU Region 1 [42]), 153-281 kHz is also used for AM BC, primarily by governments. Transmitter powers in the range of $50 \mathrm{~kW}$ to $2 \mathrm{MW}$ provide regional coverage, often with lower attenuation due to better propagation over the conductive ground.

C. Shortwave BC 
The frequency range of 3 to $26 \mathrm{MHz}$ (often called the HF band) contains sub-bands allocated to a number of stations throughout the world. It is mainly used by stations with a national interest such as the Voice of America, Radio Moscow, or Deutsche Welle, to name a few. Traditionally, the signals are amplitude modulated with audio bandwidths of $5 \mathrm{kHz}$, although HF broadcasters may also transmit digital signals using the Digital Radio Mondiale ${ }^{\mathrm{TM}}$ (DRM) method. The DRM system uses COFDM (Coded OFDM). All of the OFDM carriers are contained within the allotted transmission channel, with time interleaving to mitigate fading. DRM30 is intended for the existing AM broadcast band based on $9 \mathrm{kHz}$ or $10 \mathrm{kHz}$ channel spacings. It also has modes requiring only $4.5 \mathrm{kHz}$ or $5 \mathrm{kHz}$ bandwidth, as well as modes that can take advantage of wider bandwidths, such as $18 \mathrm{kHz}$ or $20 \mathrm{kHz}$. HF broadcast transmitters use either solid-state (5-kW modules) or vacuum-tube RF PAs, with power levels ranging from $10 \mathrm{~kW}$ to $2 \mathrm{MW}$. Directional antennas beam the programming to the target audience.

\section{FM BC}

FM BC is available worldwide (88-108-MHz band in the U.S.) and offers greatly reduced noise and interference, as well as lower distortion and larger audio bandwidth than its AM counterpart. The modulating signal is a composite of the primary audio and subcarriers. The main audio signal [(left+right $(\mathrm{L}+\mathrm{R})$ ] modulates the RF carrier with $15 \mathrm{kHz}$ audio bandwidth with $\pm 75-\mathrm{kHz}$ deviation. By adding a $19-\mathrm{kHz}$ pilot subcarrier and $38-\mathrm{kHz}$ subcarrier with $\mathrm{DSB} / \mathrm{SC}$ modulation of the $\mathrm{L}+\mathrm{R}$ signal, stereo transmission is also possible. Background music and the radio data system (RDS) can be transmitted using additional subcarriers. Channel spacing is $200 \mathrm{kHz}$, but FM stations that are geographically located near each other are assigned frequencies no closer than $400 \mathrm{kHz}$ apart to allow more guard band for filter rejection in the FM receiver.

FM broadcast in the U.S. also has an HD Radio digital signal option using the iBiquity system, which occupies sidebands above and below the center frequency. OFDM subcarriers are used, with specific modulation parameters that maintain signal bandwidth within the limits of the channel. Audio quality is equal to a CD recording. FM HD Radio may provide programming that is different from the main channel. The output power for commercial stations typically varies from 1 to $50 \mathrm{~kW}$. Solid-state PAs (see Fig. 5 in [1]) are used to the 5-kW level and vacuum-tube PAs are used for higher power levels. Antenna gain typically boosts the effective radiated power (ERP) by using multiple elements to compress the vertical radiation pattern. The antenna heights vary from 50 to $500 \mathrm{~m}$, allowing coverage slightly beyond line of sight (LOS) to distances as far as $100 \mathrm{~km}$.

E. Television (TV)

Television BC in the U.S. uses both VHF and UHF bands (54-72, 76-88, 174-216, and 470-806 MHz). With the advent of digital television (DTV), U.S. station channels were mainly 
reassigned to the UHF band, with former VHF stations allowed to return to VHF when it was determined that coverage was reduced at the higher frequency. Television transmitters power levels range from $100 \mathrm{~W}$ to $50 \mathrm{~kW}$. VHF and lower power UHF transmitters are mostly based upon solid-state PAs, while high-power UHF transmitters employ vacuum tubes. The coverage area is similar to that of FM broadcast; i.e., to about $100 \mathrm{~km}$.

Beginning in 1998, DTV commenced in the U.S., using a system based on MPEG-2 video coding and Dolby AC-3 audio coding as specified by the Advanced Television Systems Committee (ATSC) [43]. NTSC analog television in North American essentially ceased in 2009, with only a few low power TV stations still transmitting an analog signal. Digital television transmission provides higher resolution and multiple programs from the same station. A typical station will transmit a primary high definition (HD) channel along with one or two standard definition (SD) channels. Digital transmission eliminates most interference, resulting in a picture that is perfectly received as long as the SNR is sufficient. To reduce the effects of multipath, data are transmitted at relatively slow rates on multiple carriers using OFDM. The transmitter power is about the same or slightly lower than that for analog television. In the U.S., the DTV image is composed of 1080 lines with 1920 pixels per line, resulting in a data rate of $19.39 \mathrm{Mb} / \mathrm{s}$, which expands to $30.28 \mathrm{Mb} / \mathrm{s}$ with the addition of error-correction coding and other overhead. The 8VSB transmitted signal is based upon eight-level DSB/SC modulation followed by filtering to remove most of the lower sideband, allowing it to fit into existing 6-MHz television channels. In the U.K., digital video broadcasting (DVB) is based upon MPEG encoding and OFDM using 16 or 64 QAM. The data at rates up to $31.7 \mathrm{Mb} / \mathrm{s}$ are distributed among 1704 carriers with 1.1-kHz spacings or 6816 carriers with $4.5-\mathrm{kHz}$ spacings.

\section{F. Cable Television (CATV)}

CATV, originally called “community antenna television,” originated in 1950 as a means of providing local distribution of broadcast content in poor receptions area. Cable television is now present in most cities and carries not only signals from local over-the-air broadcasts, but hundreds of additional channels of programming as well. The CATV industry is in the process of transitioning from obsolete NTSC-format channels to a fully digital system that supports high definition programming, multiple audio channels, and programming-on-demand. Both the older analog and the newer digital systems support high-speed Internet access. CATV offers hundreds of channels, operating mainly in the frequency range from $50 \mathrm{MHz}$ to $1 \mathrm{GHz}$. The downstream (provider-to-user) path for TV channels and high-speed data is at frequencies above $50 \mathrm{MHz}$, with upstream (user-to-provider) communications operating below $50 \mathrm{MHz}$.

CATV may use a coaxial RF distribution system, a hybrid fiber-coax (HFC) system, or fiber-to-the-premises (FTTP). In RF-based systems, distribution amplifiers typically produce 1$10 \mathrm{~W}$ and must be both broadband and highly linear to avoid producing cross-modulation 
products on analog systems, or to maintain low error rates with the 64-QAM or 256-QAM modulation formats used for digital signals.

G. Satellite Digital-Audio Broadcast (DAB)

In 2008, the two U.S. satellite radio broadcasters, XM Satellite Radio and Sirius Satellite Radio merged into a single entity, Sirius XM Radio. Now the only U.S. satellite radio service, this system operates in S-Band-XM Radio satellites at 2,332.50 through 2,345.00 MHz, and Sirius Radio satellites at 2,320.00 through 2,332.50 MHz. Elsewhere in the world, satellite radio systems that were begun the late 1990s and early 2000s have mostly been decommissioned.

\section{MAGNETIC RESONANCE IMAGING (MRI)}

The basic physics underlying MRI is based on the application of an RF pulse (and its corresponding B1 magnetic field component) at the specific precession or Larmor frequency of nucleons placed in a high static B0 magnetic field (Fig. 24). This B1 field can provide sufficient energy to 'flip' the Net Magnetization Vector (NMV) from its longitudinal alignment with the B0 field into the transverse plane ( $90^{\circ}$ flip angle) and subsequent pickup by one or more receive coils. In one sense, the MRI system can be thought of as a transponder system where the nucleons re-transmit the energy received from the transmitter.

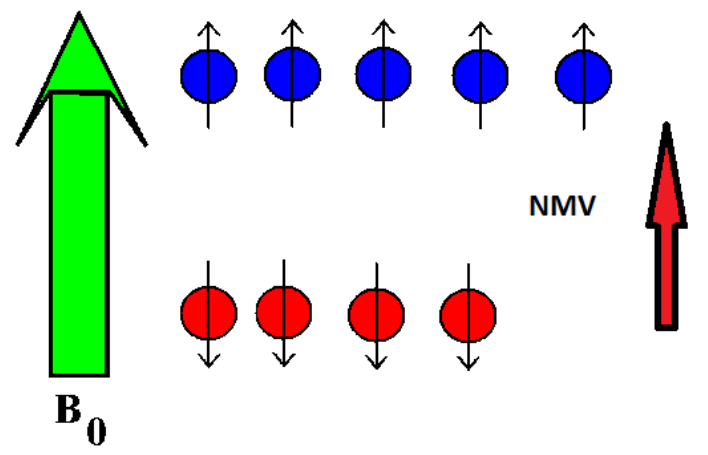

$\mathrm{a}$

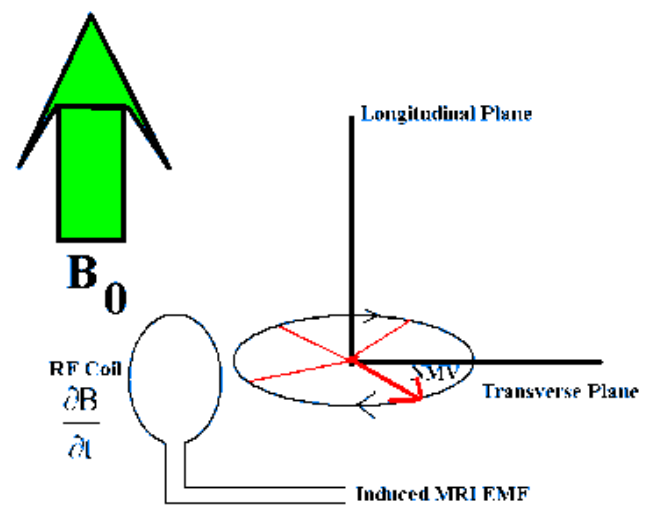

$\mathrm{b}$

Fig. 24. a) NMV is parallel with the static B0 field without an applied RF pulse; b) the NMV 'flips' into the transverse plane after application of an RF pulse and induces an EMF in the receive pickup coil. 
The magnitude of the NMV is directly related to the strength of the B0 field and the ratio of the number of 'spin-down' high-energy nucleon magnetic moments $n^{-}$to the 'spin-up' lower energy nucleon magnetic moments $\mathrm{n}^{+}$:

$\frac{n^{-}}{n^{+}} \propto e^{-\frac{h y B 0}{k T}}$

Where $\gamma$ is the gyromagnetic ratio. In turn, the received signal strength is directly related to the magnitude of the NMV so that increasing the B0 field will provide stronger signal returns from the imaging area and hence increase the SNR. Increasing B0, however, also increases the Larmor frequency, which for single proton hydrogen ${ }_{1} \mathrm{H}$ is $42.6 \mathrm{MHz} /$ Tesla. MRI scanners use superconducting solenoid coil assemblies to generate the high static and homgenous B0 fields; highest field uniformity is in the central region of the solenoid or the so-called magnet bore (Fig. 25 shows an example). Current research trends for human studies using MRI look to $7 \mathrm{~T}$ and 10.5 T superconducting magnets to improve image quality, with the associated RF electronics working at 298 and $447 \mathrm{MHz}$, respectively. The higher frequencies of operation also operate in a higher loss regime and so higher power amplifiers are required at these high B0 field strengths (see Fig 4 for an example of an MRI RF PA suitable for use at B0 $=1.0 \mathrm{~T}$ for ${ }_{1} \mathrm{H}$ and Fig. 5 for a MRI RF PA for 10.5T). This can lead to interesting design issues throughout the system.

Various RF pulse sequences have been developed to enhance contrast from the region of interest (ROI). Some combination of pulse repetition rate (TR) and time delay for receive (echo time or $\mathrm{TE}$ ) provide the RF conditions for the enhanced contrast. Because the signals re-radiated from the nucleons are at the same frequency of the high power transmit pulse, short TE pulse sequences often require that the PA output be blanked so that any tail in the RF pulse is removed so that the weak MR return can be received. The only control component that can handle both the nanosecond switching speed and kilowatt power levels are PIN diodes. High B0 MRI systems use TEM or microstrip transmit coils instead of traditional birdcage coils because only the TEM/microstrip coils provide the bore size and B1 field required. Research continues to be done with TEM coils since they lend themselves more readily to EM field shaping to improve homogeneity or to minimize field strength in non-ROI areas. 


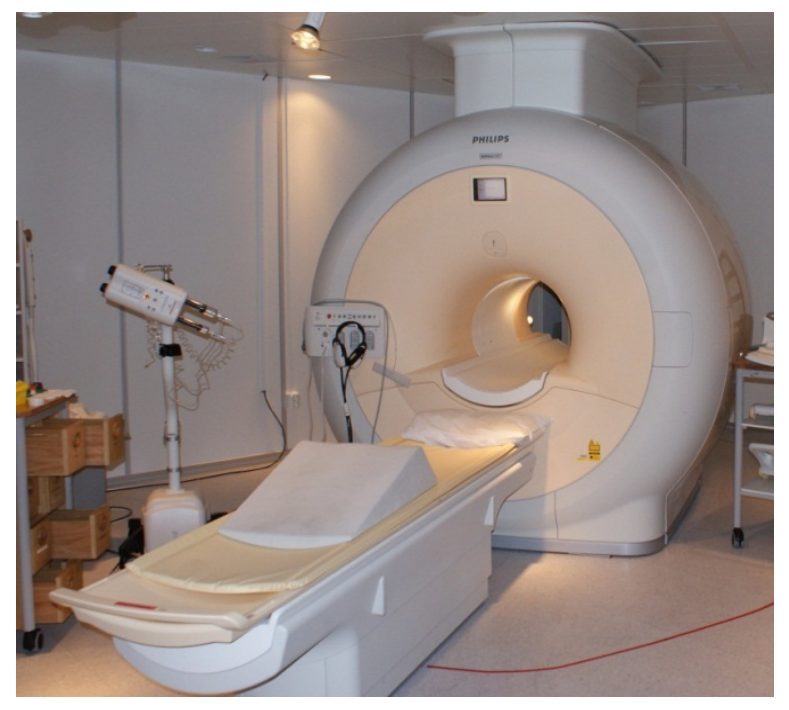

Figure 25. High field MR scanner with solenoid high field coil [44].

The receive side of the MR system is also of significant research interest. With the weak nucleon return signal, SNR is a major system parameter. Research has shown that small diameter receive coils may pick up less signal but also pick up less noise. In addition to reduced signal pickup, major signal pickup only occurs within approximately the radius of the coil and so different receive coils or receive coil arrays are used for imaging various subject areas. In all cases, to maximize the signal pickup, the coil arrays are placed in close contact with the subject. Care must be taken here because the receive coils are tuned to the same frequency as the transmit pulse. Protection circuits are incorporated to detune the coils during transmit to minimize heating and potential burns to the subject and also to protect sensitive electronics. Again, PIN diodes are used on the receive side since they provide the high switching speeds needed. From noise theory, LNAs should be placed as close to the antenna (or in the MRI case, the receive coil or array). This also applies to MR systems. LNAs are placed with the same receive coil array; as such, the electronics are within the high B0 field. The electronics need to have very low magnetic properties to minimize image distortion/artifacts due to their residual magnetization. PIN diodes for use in MR systems continue to be researched, with low magnetic moment packaged devices receiving the bulk of the attention. Because of the high powers used in MR scanners, electrothermal modeling of the PIN diodes can give designers a priori knowledge of the potential destructive effects of excessive temperature rise in the devices during high power pulse periods (Fig. 16). Changes in circuit design can be done to ensure the devices' survival. This is especially crucial in the receive side of the MR scanner since these diodes are used as blockers (or limiters) for LNA protection as well as receive coil detuning to prevent unwanted coupling to the transmit coil and also for patient protection during the high RF pulse period (Fig. 26). 


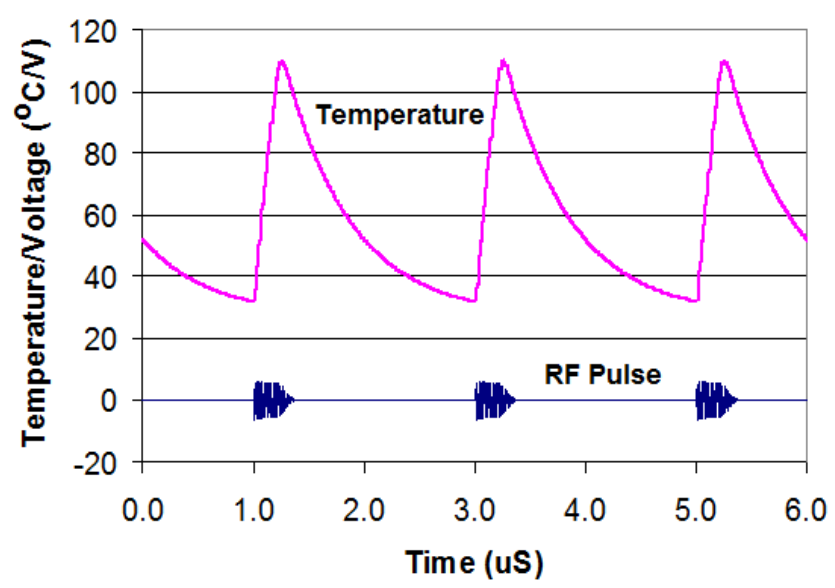

Fig. 26. Simulated transient temperature rise in PIN diode receive coil blocker [45].

Smaller bore magnets up to $16.4 \mathrm{~T}$ for small animal studies are being used with RF electronics up to $699 \mathrm{MHz}$. These high field applications are well into the UHF range. The National High Magnetic Field Laboratory and affiliated groups in Florida are pushing to even higher fields, with small animal MRI using high field $21 \mathrm{~T}$ magnets requiring electronics operating at $900 \mathrm{MHz}$.

\section{GROUND PENETRATING RADAR}

The use of radar at microwave frequencies for detection and range information for aboveground objects is a well-established technology with a rich history. A somewhat different use of radar for belowground imaging, while not as widely known, finds use in a number of specialized fields. Ground penetrating radar (GPR) is similar to above ground radar where RF pulses are directed at perspective targets with time delay and other information used to provide images of the objects. In contrast to aboveground radar, the propagation environment can be much more hostile. Conductive and dielectric properties of the ground vary dramatically. Soils with high moisture content show high attenuation, and so GPR systems that probe into the earth are usually limited to a few hundred MHz. The term GPR is also used when RF imaging other materials (with lower moisture content) such as concrete or asphalt. GPR is used in a number of applications such as archeology, locating buried structures and utility lines, location of land mines, tunnels, and buried military munitions, and in the study of landfills [46-48] (Fig. 27). Other applications include drilling hole (or borehole) investigations. No matter the application, GPR is still based on the fundamental principles of E\&M but with the waves potentially traveling in a high loss and dispersive media. For RF imaging in soils, the transmission medium can vary dramatically from one location to the next. The ground can be composed of soil grains interspersed with air (such as a desert environment) or with moisture (water for example, at a 
beach or marshy area). Because of the high loss of RF energy in liquid water (which could also contain dissolved materials that increase losses even more), dry, sandy ground has some of the highest depths of penetration of tens of meters. Interestingly, frozen water (ice) also has a very high penetration depth. Typical GPR frequencies for normal ground imaging use the HF through VHF and low UHF frequency bands. For objects with extremely low water content (such as assisting in monitoring the health of concrete structures), higher frequencies (up to $2.4 \mathrm{GHz}$ ) have been used. The properties of materials used for imaging can range from dielectric constants of 81 (water) with conductivities as high as $100 \mathrm{~S}$ in seawater to dielectric constants of 1 or 2 and low conductivities $0.05 \mathrm{~S} / \mathrm{m}$ in asphalts and concretes. A number of empirical relationships are used that relate the medium conductivity its porosity and brine saturation (Archie's Law) and to the dielectric constant as a function of water content (Topp Relationship). Lower frequency RF imaging can 'see' down to 30-40 m but with low resolution and so are used to identify large structures buried deeply. Higher frequency signals suffer from more attenuation and have small imaging depths but with increased resolution. This is helpful in identifying smaller features.

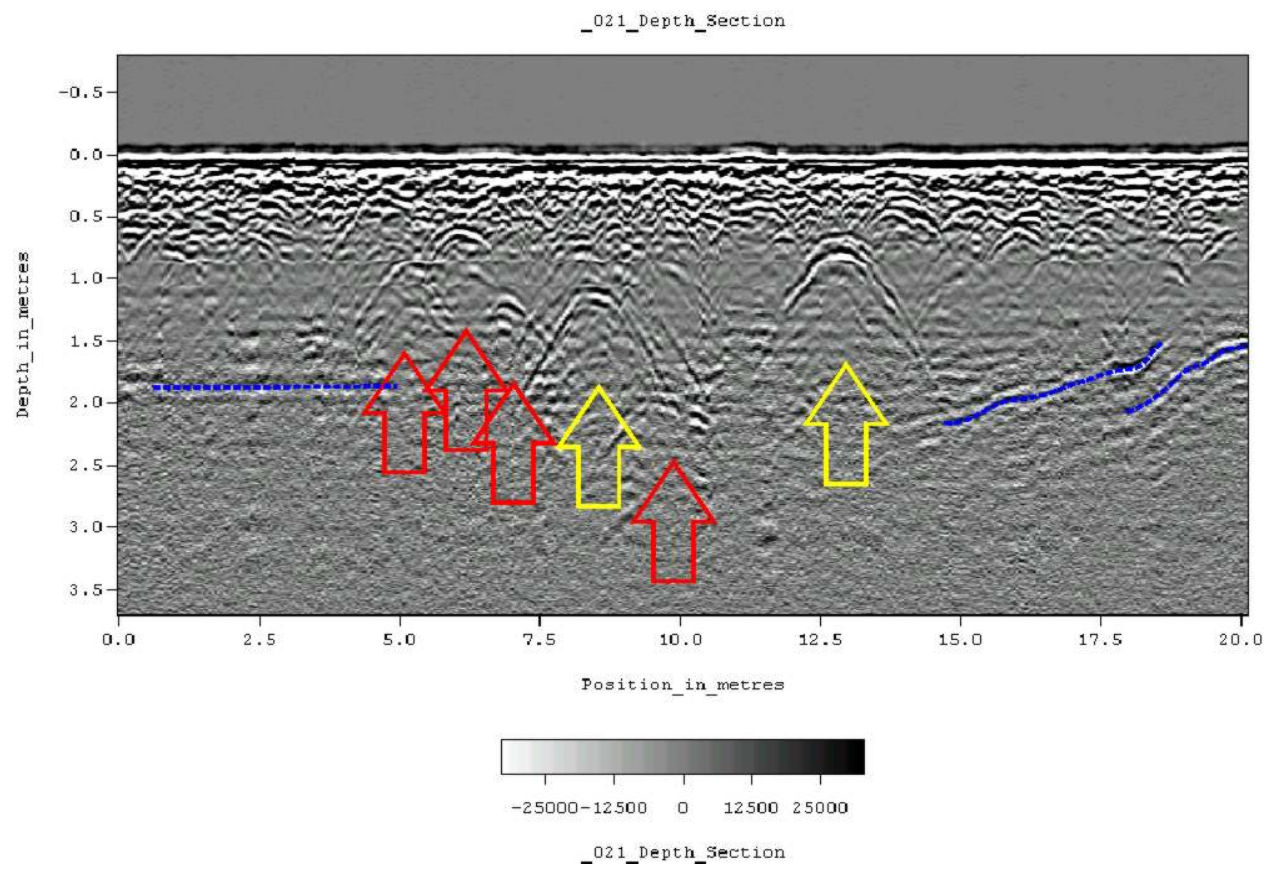

Fig. 27. GPR results showing classic hyperbolic-shaped returns [49].

A typical soil-based GPR system contains a transceiver, antennas and imaging electronics on a mobile platform that allows the operator to roll the equipment in a structured grid pattern (Fig 28). Other systems used for imaging more localized structures can be placed near the location of interest. In most GPR systems, the antennas are placed very close to the air-ground interface so that reflection from the air-ground interface has a very short time delay (surface lines at $0.0 \mathrm{~m}$ depth in Fig. 27); the imaging electronics must be timed to separate the air and ground 
waves from the desired reflected wave (Fig 29). Radial resolution of GPR systems is primarily dependent on the RF pulse bandwidth whereas lateral resolution is more dependent on transmit center frequency. Probing at larger depths involves dealing not only with the attenuation characteristics of the medium but also scattering effects, whereas probing at shallow depths implies fast electronics because of the short echo delay. Fig. 27 is a representative GPR image showing the classic hyperbolic returns from discrete buried objects as well as immediate subsurface reflections. A specific area is mapped by physically moving the GPR system along a defined grid pattern .

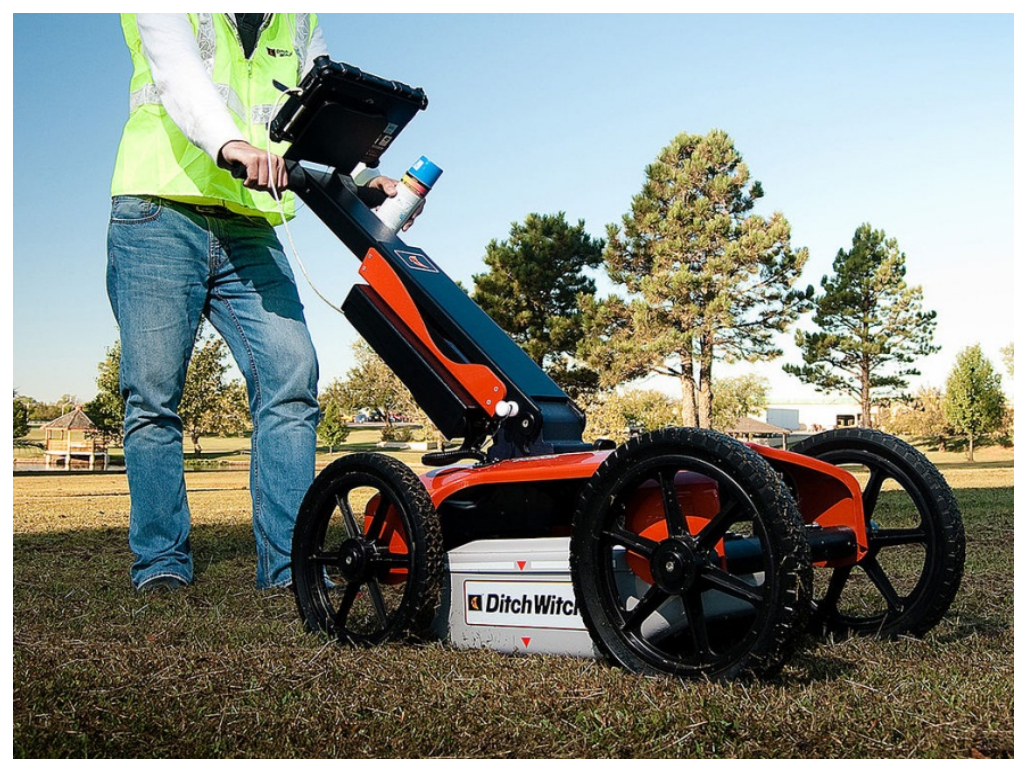

Fig. 28. GPR system in use [50]

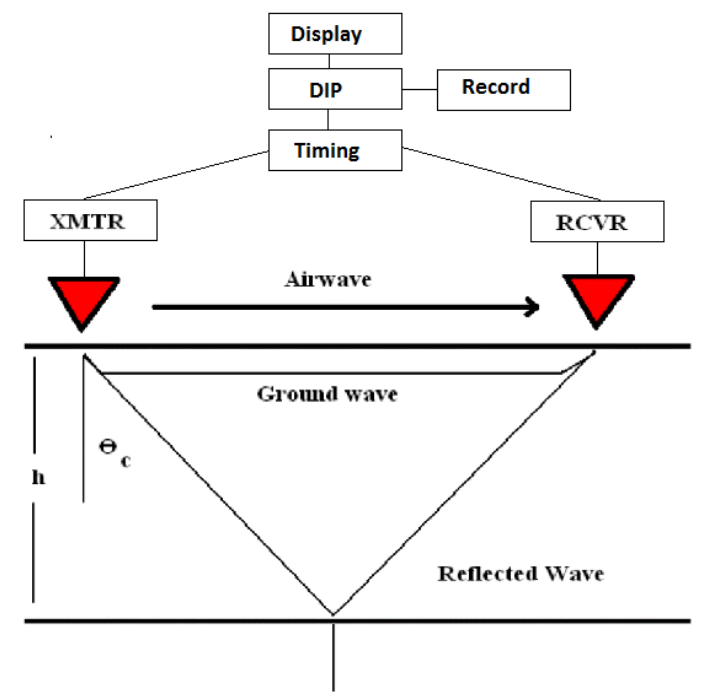

Figure 29. Ray diagram of GPR system showing the air, ground and reflected waves and the positioning of the transceiver and associated electronics. 


\section{Over the Horizon Radar}

Over-the-horizon Radar (OTH Radar) allows HF signals in the roughly 3-30 MHz range to use ionospheric reflections to provide tracking of targets thousands of km away, well beyond the range of microwave radars. Early OTH radars used FM-CW techniques with chirp frequencies of $5-100 \mathrm{kHz}$ and repetition rates of $10-60 \mathrm{~Hz}$ to obtain range, direction, amplitude, and Doppler shift. The original 2002 article covered two such OTH systems, the U.S. Air Force OTH-B system, currently in an inactive, but ready state, and the U.S. Navy Relocatable Overthe-Horizon Radar (ROTHR). Other OTH systems in use include the French NOSTRADAMUS system [51, 52] and the Jindalee OTH system in Austrialia [53, 54]. OTH radar systems typically use large phased arrays of monopoles or dipoles that can extend over several $\mathrm{km}$. The transmitting phased array is usually excited with 5 to $20-\mathrm{kW}$ of power to each element in the array to produce a total transmitter power of $0.5-1 \mathrm{MW}$, with a beam that can be scanned over a few tens of degrees. A receiving antenna is located some distance (usually 100-200 km from the transmitter) and also is a phased array system. The basic transmission system using chirped FM has not changed much since 2002, but there has been significant work in new areas of signal processing to improve OTH performance. Space-time adaptive processing (STAP) [55, 56] and cognitive radar [57-59] techniques for example, are now being used to improve and reduce multi-path interference. Since the standard OTH radar system contains multiple transmit and multiple receive antennas, multiple input multiple output (MIMO) techniques $(60,61)$ can be used in beamforming to mitigate signal clutter. Work continues on improving geolocation of targets when real-time ionospheric path information is not readily available [62].

\section{CONCLUSION}

There have been quite a number of advances in technology below $1000 \mathrm{MHz}$ in the dozen years since the 2002 T-MTT article was published [1]. This article has been an attempt to update or introduce a number of technology areas in the sub-1000 MHz frequency range. The article updated technologies such as RF transistors, high power amplifiers, receivers and MRI techniques. Since 2002, other technologies have become more widespread such as ground penetrating radar, or there has been improved understanding of electromagnetic compatibility and minimization of undesired circuit interactions. It will be exciting in the next dozen years to see the advances on based on the technologies outlined in this article. A number of areas outlined in this paper such as diamond semiconductors or software defined radio technology could have dramatic impact in the near future and spawn new applications and understandings. A statement by Tim O’Reilly certainly supports this idea:

What new technology does is create new opportunities to do a job that customers want done. 


\section{REFERENCES}

[1]. Raab, F.H.; Caverly, R.; Campbell, R.; Eron, M.; Hecht, J.B.; Mediano, A; Myer, D.P.; Walker, J. L B, "HF, VHF, and UHF systems and technology," Microwave Theory and Techniques, IEEE Transactions on , vol.50, no.3, pp.888,899, Mar 2002.

[2]. Pomeroy, J.; Bernardoni, M.; Sarua, A; Manoi, A; Dumka, D.C.; Fanning, D.M.; Kuball, M., "Achieving the Best Thermal Performance for GaN-on-Diamond," Compound Semiconductor Integrated Circuit Symposium (CSICS), 2013 IEEE , vol., no., pp.1,4, 13-16 Oct. 2013.

[3] R. H. Caverly, Drozdovski, N. ; Quinn, M., "High power effects in gallium nitride-based microwave and RF control devices”, Proc. IEEE 2000 Radio and Wireless Conference (RAWCON 2000), pp. 151154.

[4]. J. Custer and J. Walker, “A 100W Decade Bandwidth, High-Efficiency GaN Amplifier”, European Microwave Conference, Rome, Italy, 7-9th October, 2014.

[5]. Chen, W.; Chinga, R. A; Yoshida, S.; Lin, J.; Chen, C.; Lo, W., "A 25.6 W 13.56 MHz wireless power transfer system with a 94\% efficiency GaN Class-E power amplifier," Microwave Symposium Digest (MTT), 2012 IEEE MTT-S International , vol., no., pp.1,3, 17-22 June 2012.

[6]. M.Kasu, "Diamond Field-Effect Transistors as Microwave Power Amplifiers” NTT Technical Review, vol. 8, pp. 1-5, Aug. 2010.

[7] Steinbeiser, C.; Page, P.; Landon, T.; Burgin, G., "Doherty Power Amplifiers Using 2nd Generation HVHBT Technology for High Efficiency Basestation Applications," Compound Semiconductor Integrated Circuit Symposium (CSICS), 2010 IEEE , vol., no., pp.1,4, 3-6 Oct. 2010.

[8] Y. Yang, J. Yi, Y. Yun Woo and B. Kim, "Optimum Design for Linearity and Efficiency with a new Load Matching Technique", Microwave Journal, Vol. 44, No. 12, pp. 20-36, 2001.

[9] M. Ozen, R. Jos, C.M. Anderson, M. Acar and C. Fager, "High Efficiency RF Pulse Width Modulation of Class-E Power Amplifiers", IEEE Transaction on MTT, Vol. 59, No. 11, pp. 2931-2942, November, 2011.

[10] J. Staudinger, G. Bouisse, J. Kinney, "High efficiency 450W asymmetric three device Doherty amplifer with digital feedback predistortion’, Proc. IEEW Radio Wireless Symp. 2010, pp. 116-119.

[11] F. H. Raab, M. C. Poppe III, and D. P. Myer, "High-efficiency linear power-amplifier module for magnetic-resonance imaging," Paper 1850, Proc. Intl. Soc. Mag. Reson. Med. 19, Paper 1850, Montreal, May 7 - 13, 2011.

[12] P. Marchand, R. Lopes, F. Ribeiro, T. Ruan, “ Development of High Power RF Power Solid-state Amplifiers at SOLEIL”, Proc. IPAC2011, pp. 376-378, 2011.

[13] A. Averburg, K. R. Meyer, C. Q. Nguyen, and A. Mertens, “A survey of converter topologies for fuel cells in the KW range,” in Proc. IEEE Energy 2030 Conf., 2008. 
[14] M. Bertoluzzo, N. Zabihi, G. Buja, “Overview on battery chargers for plug-in electric vehicles,” in Proc. $15^{\text {th }}$ Int. Power Electronics and Motion Control Conf., 2012.

[15] M. K. Kazimierczuk, Pulse-Width Modulated DC-DC Power Converters, John Wiley \& Sons, 2008.

[16] R. Tymerski and V. Vorpérian, "Generation and classification of PWM DC-to-DC converters," IEEE Trans. Aerospace and Electronic Systems, vol. 24, no. 6, pp. 743-754, Nov. 1988.

[17] M. K. Kazimierczuk, D. Q. Vuong, B. T. Nguyen, and J. A. Weimer. "Topologies of bidirectional PWM dc-dc power converters,” in IEEE National Proc. Aerospace and Electronic Conference, 1993, pp. 435-441.

[18] C.-C. Lin, Y. Lung-Sheng, G. W. Wu, "Study of a non-isolated bidirectional dc-dc converter,” IET Proc. Power Electronics, vol. 6, no. 1, pp. 30-37, Jan. 2013.

[19] D. A. Grant, Y. Darroman, and J. Suter, "Synthesis of tapped- inductor switched-mode converters," IEEE Trans. Power Electronics, vol. 22, no. 5, pp. 1964-1969, Sept. 2007.

[20] B. W. Williams, "Unified synthesis of tapped inductor dc-to- dc converters," IEEE Trans. Power Electronics, vol. 29, no. 10, pp. 5370 - 5383, Oct. 2014.

[21] F. H. Raab, P. Asbeck, S. Cripps, P. B. Kenington, Z. B. Popovic, N. Pothecary, J. F. Sevic, and N. O. Sokal, "Power Amplifiers and Transmitters for RF and Microwave," IEEE Trans. Microwave Theory \& Tech., vol. 50, no. 3, pp. 814-826, March 2002.

[22] P. Lavrador, T. R. Cunha, P. Cabral, and J. C. Pedro, “The Linearity-Efficiency Compromise,” IEEE Microwave Mag., vol. 11, no. 5, pp. 44-58, Aug. 2010.

[23] E. McCune, "Envelope Tracking or Polar-Which Is It? [Microwave Bytes]," IEEE Microwave Mag., vol. 13, no. 4, pp. 34-56, June 2012.

[24] F. H. Raab, “Split-Band Modulator for Kahn-Technique Transmitters," in IEEE MTT-S Int. Microw. Symp. Dig., June 2004, pp. 887-890.

[25] N. Wang, X. Peng, V. Yousefzadeh, D. Maksimovic, S. Pajic, and Z. Popovic, "Linearity of Xband Class-E Power Amplifiers in EER Operation,” IEEE Trans. Microwave Theory \& Tech., vol. 53, no. 3, pp. 1096-1102, March 2005.

[26] F. Wang, D. F. Kimball, J. D. Popp, A. H. Yang, D. Y. Lie, P. M. Asbeck, and L. E. Larson, “An Improved Power-Added Efficiency 19-dBm Hybrid Envelope Elimination and Restoration Power Amplifier for 802.11g WLAN Applications,” IEEE Trans. Microwave Theory \& Tech., vol. 54, no. 12, pp. 4086-4099, Dec. 2006.

[27] D. Kang, D. Kim, J. Choi, J. Kim, Y. Cho, and B. Kim, “A Multimode/Multiband Power Amplifier with a Boosted Supply Modulator,” IEEE Trans. Microwave Theory \& Tech., vol. 58, no. 10, pp. 2598-2608, Oct. 2010. Tech., vol. 58, no. 10, pp. 2598-2608, Oct. 2010.

[28] N. Le Gallou, D. Sardin, C. Delepaut, M. Campovecchio, and S. Rochette, “Over $10 \mathrm{MHz}$ Bandwidth Envelope-Tracking DC/DC Converter for Flexible High Power GaN Amplifiers,” in IEEE MTT-S Int. Microw. Symp. Dig., June 2011, pp. 1-4. 
[29] S. Shinjo, H. Young-Pyo, H. Gheidi, D. F. Kimball, and P. M. Asbeck, "High Speed, High analog Bandwidth Buck Converter using GaN HEMTs for Envelope Tracking Power Amplifier Applications," in IEEE Topical Conf. Wireless Sensors and Sensor Networks (WiSNet), Jan. 2013, pp. 13-15.

[30] R. Marante, M. N. Ruiz, L. Rizo, L. Cabria, and J. A. García, “A UHF Class E² DC/DC Converter using GaN HEMTs,” in IEEE MTT-S Int. Microw. Symp. Dig., June 2012, pp. 1-3.

[31] J. A. García, R. Marante, and M. N. Ruiz, “GaN HEMT Class E² Resonant Topologies for UHF DC/DC Power Conversion,” IEEE Trans. Microwave Theory \& Tech., vol. 60, no. 12, pp. 4220-4229, Dec. 2012.

[32] M. K. Kazimierczuk, J. Jozwik, "Resonant DC/DC Converter with Class-E Inverter and Class-E Rectifier," IEEE Trans. Ind. Electron., vol. 36, no. 4, pp. 468-478, Nov. 1989.

[33] M. K. Kazimierczuk and J. Jozwik, “Class E ${ }^{2}$ Narrow-Band Resonant DC/DC Converters,” IEEE Trans. Instrum. Meas., vol. 38, no. 6, pp. 1064-1068, Dec. 1989.

[34] M. K. Kazimierczuk and D. Czarkowski, Resonant Power Converters, NJ: John Wiley \& Sons, 2011.

[35] R. W. Erickson and D. Maksimovic, Fundamentals of Power Electronics, $2^{\text {nd }}$ ed., Kluwer Academic Press, New Yori, 2001.

[36] F. H. Raab, "Idealized operation of the class E tuned power amplifier," IEEE Trans. Circuits and Syst., vol. 24, no. 12, pp. 725- 735, Dec. 1977.

[37] T. B. Mader, Z. B. Popovic, "The transmission-line high-efficiency class-E amplifier," IEEE Microw. Guided Wave Lett., vol. 5, no. 9, pp. 290-292, Sep 1995; see also: R. Beltran and F. H. Raab, "Lumped-Element Output Networks for High-Efficiency Power Amplifiers, IEEE MTT-S Int. Microwave Symp., May 2010, pp. 324-327.

[38] R. Negra and W. Bächtold, "Lumped-element Load-network Design for Class-E Power Amplifiers," IEEE Trans. Microwave Theory \& Tech., vol. 54, no. 6, pp. 2684-2690, June 2006.

[39] J. A. García, R. Marante, M. N. Ruiz, and G. Hernández, “A 1 GHz Frequency-controlled Class $E^{2}$ DC/DC Converter for Efficiently Handling Wideband Signal Envelopes,” in IEEE MTT-S Int. Microw. Symp. Dig., June 2013, pp. 1-4.

[40] - H. W. Ott, Noise Reduction Techniques in Electronic Systems, 2nd Edition, Wiley \& Sons, Mar 1988.

[41] - W. H. Cantrell, “EMI/EMC Fundamentals for RF/MW Engineers,” Half-Day Tutorial, IEEE 2012 International Microwave Symposium MTT-S, June 22, 2012, Montréal, Canada.

[42] http://www.itu.int/

[43] Fox, B., "Digital TV rollout [US digital terrestrial TV]," Spectrum, IEEE , vol.38, no.2, pp.65,67, Feb 2001.

[44] (Source: Wikipedia Commons - http://en.wikipedia.org/wiki/File:MRI-Philips.JPG). 
[45] R. Caverly, 'Electrothermal Modeling of PIN Diode Protection Circuits in MRI Surface Coils', 2014 IEEE Topical Conference on Biomedical Wireless Technologies, Networks, and Sensing Systems (BioWireleSS2014), Jan. 2014.

[46] Ground Penetrating Radar, 2nd ed., D. Daniels, ed., IEE Press, 2004.

[47] Ground Penetrating Radar: Theory and Applications., H. Jol, ed., Elesevier Science, 2009.

[48]

http://www.epa.gov/esd/cmb/GeophysicsWebsite/pages/reference/methods/Surface_Geophysical_Method s/Electromagnetic_Methods/Ground-Penetrating_Radar.htm .

[49] User:Tapatio / Wikimedia Commons / Public Domain, http://en.wikipedia.org/wiki/File:LINE21.jpg

[50] The Charles Machine Works/Wikipedia Commons/ Creative Commons ShareAlike 2.0 Generic (CC BY-SA 2.0), http://en.wikipedia.org/wiki/File:Ground_Penetrating_Radar_in_use.jpg).

[51]. Bazin, V.; Molinie, J.-P.; Munoz, J.; Dorey, P.; Saillant, S.; Auffray, G.; Rannou, V.; Lesturgie, M., "A general presentation about the OTH-Radar NOSTRADAMUS," Radar, 2006 IEEE Conference on , vol., no., pp.9 pp.,, 24-27 April 2006

[52]. Bazin, V.; Molinie, J.-P.; Munoz, J.; Dorey, P.; Saillant, S.; Auffray, G.; Rannou, V.; Lesturgie, M., "Nostradamus: An OTH Radar," Aerospace and Electronic Systems Magazine, IEEE , vol.21, no.10, pp.3,11, Oct. 2006.

[53]. G. F. Earl, and B. D. Ward, “The frequency management system of the Jindalee over-the-horizon backscatter HF radar”, Radio Science, 22, 275-291, 1986.

[54]. A. Cameron, “The Jindalee operational radar network: its architecture and surveillance capabilities”, Proceedings IEEE International Radar conference, Arlington, Virginia, USA (2005).

[55]. Fabrizio, G.A; Farina, A, "Time-varying STAP for nonstationary hot clutter cancellation," Acoustics, Speech and Signal Processing (ICASSP), 2014 IEEE International Conference on , vol., no., pp.6062,6066, 4-9 May 2014.

[56]. Krolik, J.; Mecca, V.; Kazanci, O.; Bilik, I, "Multipath spread-Doppler clutter mitigation for overthe-horizon radar," Radar Conference, 2008. RADAR '08. IEEE , vol., no., pp.1,5, 26-30 May 2008

[57. Holdsworth, D.A, "An over-the-horizon radar performance assessment module for use in cognitive radar," Radar Systems (Radar 2012), IET International Conference on , vol., no., pp.1,6, 22-25 Oct. 2012

[58] S. Haykin, “Cognitive radar: a way of the future”, IEEE Signal Processing Magazine, 23(1), 30-40, 2006.

[59] K. Lu and X. Chen, “Cognitive over-the-horizon radar”, IEEE CIE International Conference on Radar, 2011. 
[60]. Abramovich, Y.I; Frazer, Gordon J.; Johnson, B.A, "Markov model for convergence analysis of the adaptive Kronecker MIMO OTH radar beamformer," Radar Conference, 2010 IEEE , vol., no., pp.1,5, 10-14 May 2010.

[61]. Frazer, G.J.; Meehan, D. H.; Abramovich, Y.I; Johnson, B.A, "Mode-Selective OTHR: A new costeffective sensor for maritime domain awareness," Radar Conference, 2010 IEEE , vol., no., pp.935,940, 10-14 May 2010.

[62]. Fabrizio, Giuseppe, "Geolocation of HF skywave radar signals using multipath in an unknown ionosphere," Radar Conference, 2014 IEEE , vol., no., pp.0422,0425, 19-23 May 2014 